\title{
Thalamic WNT3 Secretion Spatiotemporally Regulates the Neocortical Ribosome Signature and mRNA Translation to Specify Neocortical Cell Subtypes
}

\author{
@Matthew L. Kraushar, ${ }^{1}$ Barbara Viljetic, ${ }^{1}$ H. R. Sagara Wijeratne, ${ }^{1}$ Kevin Thompson, ${ }^{1}$ Xinfu Jiao, ${ }^{2}$ Jack W. Pike, ${ }^{1}$ \\ Vera Medvedeva, ${ }^{3}$ Matthias Groszer, ${ }^{3}$ Megerditch Kiledjian, ${ }^{2}$ Ronald P. Hart, ${ }^{2}$ and ${ }^{\circledR}$ Mladen-Roko Rasin ${ }^{1}$ \\ ${ }^{1}$ Department of Neuroscience \& Cell Biology, Robert Wood Johnson Medical School and ${ }^{2}$ Department of Cell Biology \& Neuroscience, Rutgers University, \\ Piscataway, New Jersey 08854, and ${ }^{3}$ Inserm, UMR-S839, Sorbonne Universités, Pierre et Marie Curie Université Paris 06, Institut du Fer à Moulin, Paris \\ 75005, France
}

Neocortical development requires tightly controlled spatiotemporal gene expression. However, the mechanisms regulating ribosomal complexes and the timed specificity of neocortical mRNA translation are poorly understood. We show that active mRNA translation complexes (polysomes) contain ribosomal protein subsets that undergo dynamic spatiotemporal rearrangements during mouse neocortical development. Ribosomal protein specificity within polysome complexes is regulated by the arrival of in-growing thalamic axons, which secrete the morphogen Wingless-related MMTV (mouse mammary tumor virus) integration site 3 (WNT3). Thalamic WNT3 release during midneurogenesis promotes a change in the levels of Ribosomal protein L7 in polysomes, thereby regulating neocortical translation machinery specificity. Furthermore, we present an RNA sequencing dataset analyzing mRNAs that dynamically associate with polysome complexes as neocortical development progresses, and thus may be regulated spatiotemporally at the level of translation. Thalamic WNT3 regulates neocortical translation of two such mRNAs, Foxp2 and Apc, to promote FOXP2 expression while inhibiting APC expression, thereby driving neocortical neuronal differentiation and suppressing oligodendrocyte maturation, respectively. This mechanism may enable targeted and rapid spatiotemporal control of ribosome composition and selective mRNA translation in complex developing systems like the neocortex.

Key words: mRNA translation; neocortex; ribosome; thalamocortical; Wnt

Significance Statement

The neocortex is a highly complex circuit generating the most evolutionarily advanced complex cognitive and sensorimotor functions. An intricate progression of molecular and cellular steps during neocortical development determines its structure and function. Our goal is to study the steps regulating spatiotemporal specificity of mRNA translation that govern neocortical development. In this work, we show that the timed secretion of Wingless-related MMTV (mouse mammary tumor virus) integration site 3 (WNT3) by ingrowing axons from the thalamus regulates the combinatorial composition of ribosomal proteins in developing neocortex, which we term the "neocortical ribosome signature." Thalamic WNT3 further regulates the specificity of mRNA translation and development of neurons and oligodendrocytes in the neocortex. This study advances our overall understanding of WNT signaling and the spatiotemporal regulation of mRNA translation in highly complex developing systems.

\section{Introduction}

Neocortical development is defined by precise spatiotemporal control of protein expression and activity that drives the forma-

Received Feb. 12, 2015; revised May 30, 2015; accepted June 17, 2015.

Author contributions: M.L.K. and M.-R.R. designed research; M.L.K., B.V., H.R.S.W., K.T., J.W.P., V.M., M.G., and M.-R.R. performed research; X.J. and M.K. contributed unpublished reagents/analytictools; M.L.K., H.R.S.W., R.P.H., and M.-R.R. analyzed data; M.L.K., R.P.H., and M.-R.R. wrote the paper.

This work was supported by National Institutes of Health (NIH) grants (NS064303 and NS075367) and Robert Wood Johnson Medical School (RWJMS) start-up funds to M.-R.R., R.P.H. was supported by grants from the NIH (1RC1CA147187, R21DA032984, and R21DA035594), and M.K. was supported by a grant from NIH (GM067005). tion of complex cellular networks (Molyneaux et al., 2007; Leone et al., 2008; Kriegstein and Alvarez-Buylla, 2009; Rakic, 2009; Breunig et al., 2011; Kwan et al., 2012b; DeBoer et al., 2013). Mouse neocortical neurogenesis from radial glial stem cells occurs between embryonic day (E) 11 and E18, followed by gliogen-

M.L.K. was the recipient of a Kirschstein National Research Service Award F30 NIH Fellowship (1F30MH106220-01) K.T. was supported by a National Science Foundation Integrative Graduate Education and Research Traineeship Program Fellowship (DGE0801620). We thank all current and previous members of the Rasin laboratory, as well as many colleagues on the Rutgers-RWJMS campus, for comments; Dr. Althea Stillman and Katarina Yaros for technical support; and the laboratories of Darnell, Kinzy, and Copeland for support in developing the polysome protocol. 
esis. A switch from generating primarily subcortically to intracortically projecting neurons occurs during midneurogenic E15-E16. Recent extensive work identified transcriptional programs that guide neocortical development (Ayoub et al., 2011; Belgard et al., 2011; Kang et al., 2011; Kwan et al., 2012b; Fertuzinhos et al., 2014; Miller et al., 2014). However, the question of how the transition between neocortical transcriptome to proteome is regulated remains unanswered. In particular, little is known about spatiotemporal control of post-transcriptional regulatory steps, such as mRNA translation at the level of the ribosome.

mRNA translation is highly regulated in the assembly of ribosomal machinery (Fromont-Racine et al., 2003; Henras et al., 2008; Jackson et al., 2010; Xue and Barna, 2012; DeBoer et al., 2013). In many systems, including the neocortex, levels of mRNA expression do not exactly match levels of protein expression (Thompson et al., 2010; Schwanhäusser et al., 2011; Kwan et al., 2012a; DeBoer et al., 2013), due in part to substantial translational regulation. Actively translated mRNAs associate with multiple ribosomes, called polysomes. Eukaryotic ribosomes contain a large $60 \mathrm{~S}$ and small $40 \mathrm{~S}$, two subunits that form the $80 \mathrm{~S}$ monosome. Each ribosomal subunit contains a characteristic set of ribosomal proteins (R-proteins). Distinct R-proteins have heterogeneous expression patterns, can differentially associate with translation machinery, and can modulate the translation of specific mRNAs within developing or dynamic tissues (FromontRacine et al., 2003; Mazumder et al., 2003b; Kapasi et al., 2007; Kondrashov et al., 2011; Xue and Barna, 2012; Kraushar et al., 2014, Xue et al., 2015). Ribosomopathies are associated with neurological disorders, such as RPL10 ribosomopathy, which has been found recently to be associated with microcephaly, growth retardation, and seizures in humans (Brooks et al., 2014). Recently, we reported that deletion of an RNA-binding protein, $\mathrm{HuR}$, and an eIF2 kinase, eIF2ak4, alters the composition of R-proteins in neocortical ribosomes during development (Kraushar et al., 2014). However, it is not known whether $\mathrm{R}$-proteins in the large ribosomal subunits (RPLs) or in the small ribosomal subunits (RPSs) change during the course of neocortical development, or what cues might regulate ribosome composition.

Spatiotemporal gene expression in the developing CNS is regulated by secreted signaling molecules, such as morphogens, which control cell differentiation and tissue polarity. For example, Wingless-related MMTV (mouse mammary tumor virus) integration site (WNT) family members mediate neural stem cell (NSC) proliferation, axon tract formation, and forebrain patterning (Rash and Grove, 2006; Machon et al., 2007; O'Leary et al., 2007; Kutejova et al., 2009; Choe et al., 2012). Extrinsic morphogen signaling is heavily associated with transcriptional control, but its influence on timed post-transcriptional mRNA processing in the developing brain is unclear.

The present study investigates whether extrinsic morphogen signaling from ascending thalamocortical axons regulates mRNA translation machinery and spatiotemporal gene expression in the developing neocortex. The results show that numerous R-proteins differentially associate with 40S-60S-80S and/or polysomal cytoplasmic fractions in the developing mouse

The authors declare no competing financial interests.

Correspondence should be addressed to Mladen-Roko Rasin at the above address. E-mail: roko.rasin@rutgers.edu.

DOI:10.1523/JNEUROSCI.0601-15.2015

Copyright $\odot 2015$ the authors $\quad 0270-6474 / 15 / 3510912-16 \$ 15.00 / 0$ neocortex in a spatiotemporally dependent manner. R-protein specificity in developing neocortical polysomes is controlled by WNT3 secretion from arriving thalamocortical axons at midneurogenesis. We further present an analysis of functionally related mRNA subsets that differentially associate with polysomes during neocortical development, including mRNAs encoding proteins involved in translation and transcription. One such neuronal transcription factor, Forkhead box protein P2 (Foxp2; Ferland et al., 2003; Groszer et al., 2008), and a regulator of oligodendrocyte development, Adenomatous polyposis coli (Apc, also known as CC-1; Jablonska et al., 2012; Lang et al., 2013), are likewise under translational control by thalamic WNT3. The ability of timed signals from in-growing axons to define the combinatorial composition of the ribosome and translation of specific mRNAs is a mechanism that may contribute to the spatial and temporal patterning of the CNS.

\section{Materials and Methods}

Animals. All procedures were approved by the Rutgers-Robert Wood Johnson Medical School Institutional Animal Care and Use Committee (protocol \#I12-065-10). Mice of either sex were used. Timed pregnant wild-type (WT) CD-1 mice were obtained from Charles River. Thalamic Wnt 3 conditional knock-out ( Wnt3-cKO) mice and their WT littermates were generated by crossing Wnt3-floxed mice (Barrow et al., 2003) and Kcnc2-Cre [Jackson Laboratory, $\mathrm{Tg}(\mathrm{Kcnc} 2-\mathrm{Cre}) \mathrm{K} 128 \mathrm{Stl} /$ LetJ] transgenic mice. Neocortical Wnt3-cKO mice were generated by crossing Wnt3floxed mice and Emx1-Cre [Jackson Laboratory, B6.129S2-Emx1tm1(cre)Krj/J] transgenic mice. Wnt3-Gfp mice were obtained from the Mutant Mouse Regional Resource Center [Tg(Wnt3-EGFP)KM111Gsat/Mmucd]. Gfp reporter mice were obtained from the Gene Expression Nervous System Atlas (http://www.gensat.org).

Sucrose density gradient ultracentrifugation and fractionation. After dissection of total, anterior sensorimotor, or posterior auditory-visual neocortices in ice-cold PBS and RNase-free conditions, sucrose gradient ultracentrifugation and fractionation were performed as described previously (Kraushar et al., 2014).

Mass spectrometry. Neocortical protein lysates for mass spectrometry analysis were used directly from sucrose gradient fractionations. To prepare 40S-60S-80S samples, equal volumes from gradient fractions 4, 5, 6, and 7 were pooled and mixed. Similarly, to prepare polysome samples, equal volumes from gradient fractions $9,10,11$, and 12 were pooled and mixed. A total of $2-3$ biological replicates were prepared using $\geq 3$ pooled neocortices from WT E13, E16, and postnatal (P) 0 animals or from P0 Wnt3-cKO neocortices, resulting in 16 samples. Inputs were standardized across developmental stages by volume and total protein content. Mass spectrometry was performed at the Biological Mass Spectrometry Facility of Robert Wood Johnson Medical School and Rutgers.

A multidimensional protein identification technology (MudPIT) analysis (Washburn et al., 2001) of all samples (MS3143 and MS3287) was performed against an ensemble mouse using the global proteome machine (GPM). Then, comparisons were performed using R analysis. Proteins were included in the spectral counting analysis if their GPM protein expectation score $(\log e)$ was $\leq-5$ and if they comprised $\geq 2$ unique peptides (including data containing all 26 runs). Wilson's method was used to calculate lower and upper $95 \%$ confidence intervals. Exact binomial tests were used to determine whether ratios (e.g., E13/E16 or E16/P0) were significantly different from 1.0, 1.25, 1.5, 2.0, 2.5, or 3.0. $p$ values were transformed to $q$ values to control for false discovery rates arising from multiple comparisons. Values $<0.05$ were highlighted for further analysis. We also filtered the list of pairwise comparisons to exclude proteins with combined spectra counts of $<3$. Lists of significant proteins were assessed with Kyoto Encyclopedia of Genes and Genomes (KEGG) analysis using the Database for Annotation, Visualization and Integrated Discovery (http://david.abcc.ncifcrf.gov/; Huang et al., 2009a,b).

RNA sequencing. RNA sequencing (RNAseq) submission samples were isolated from fractionation input and polysome fractions. Differential 
A

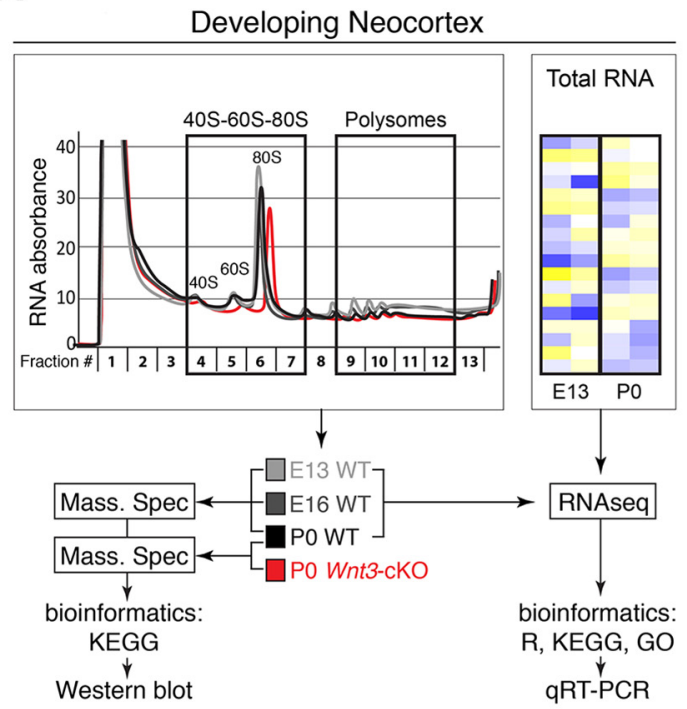

B

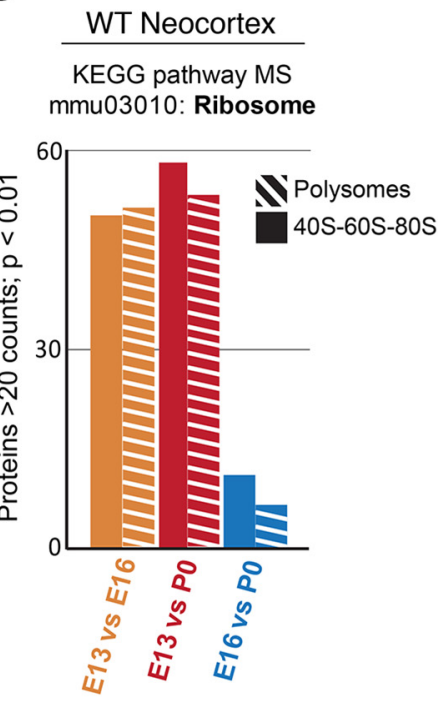

C

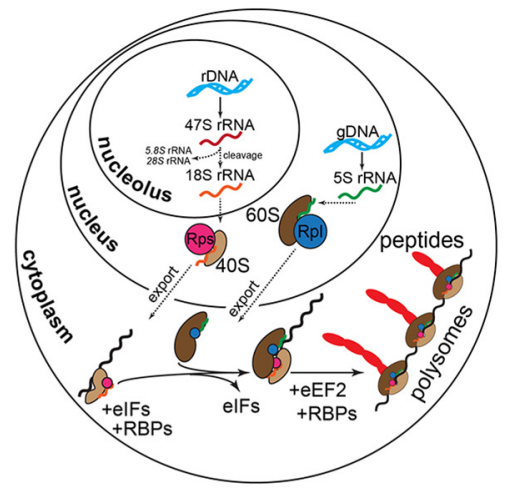

D

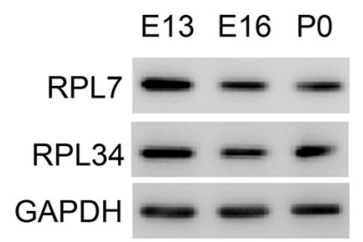

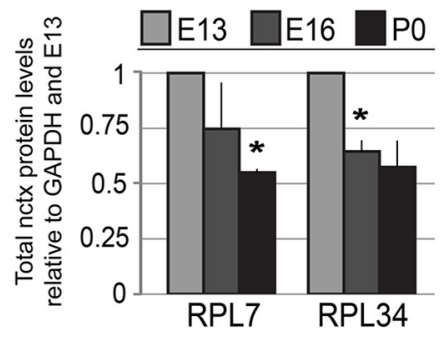

F

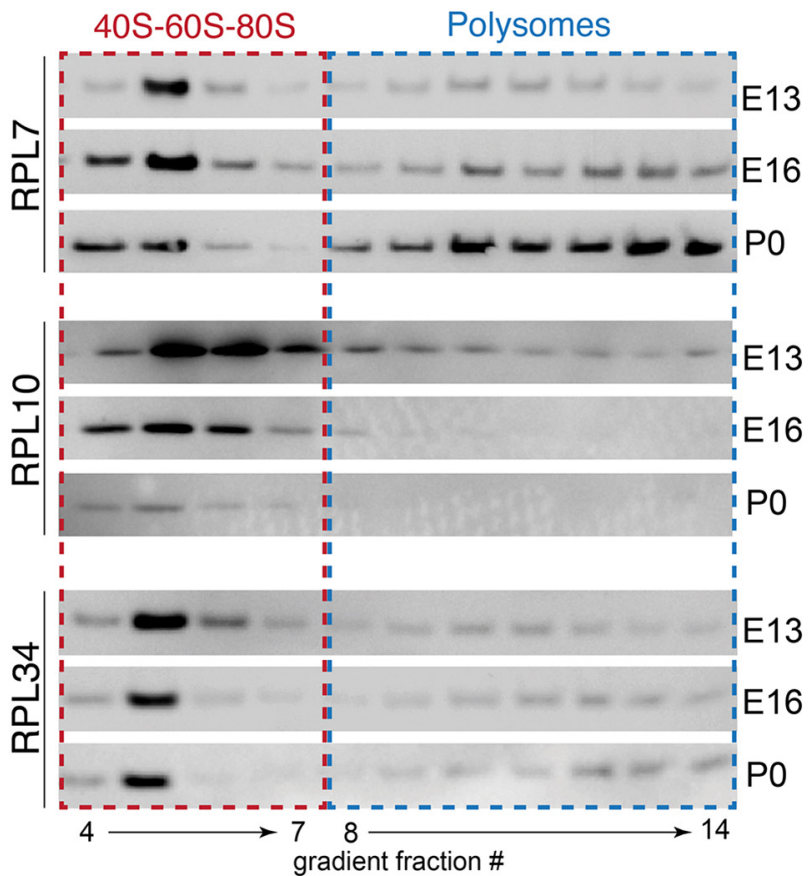

E

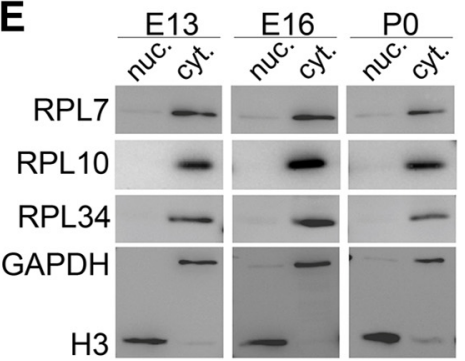

G Polysomes

40S-60S-80S
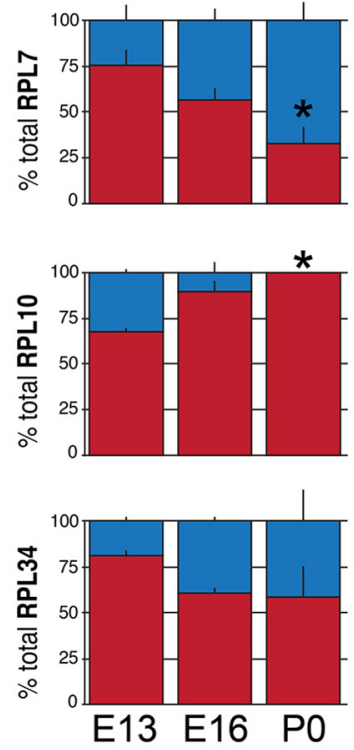

Figure 1. Neocortical 40S-60S-80S and polysomes show temporal specificity in R-protein composition. $A$, Schematic of the experimental approach used throughout our study to identify proteins and mRNAs differentially associated with 40S-60S-80S and polysomes during neocortical development. Representative density gradient curves monitored during fractionation for the conditions and stages analyzed are presented. $\boldsymbol{B}$, KEGG pathway analysis of proteins differentially expressed in WT 40S-60S-80S and polysome fractions between the E13, E16, and P0 neocortex measured by mass spectrometry with $p<0.01$. The mmu03010: Ribosome pathway represents the largest temporally dynamic group, which included predominantly ribosomal proteins. $C$, Simplified schematic of polysome biogenesis with R-protein incorporation in the nucleus and cytoplasm. D, Western blot (left) and quantification (right) ofE13, E16, and P0 total neocortical lysates for candidate R-proteins measured by mass spectrometry as changed in 40S-60S-80S and polysomes (RPL7) versus an unchanged control (RPL34; $n=3$ per stage; $t$ test, $p<0.05$ ). (Figure legend continues.) 
gene expression was then analyzed with Tophat/Cufflinks (Trapnell et al., 2012). Genes with changing levels were further analyzed using Gene Ontology (GO; Ashburner et al., 2000), KEGG (Kanehisa et al., 2014), and neocortical layer-specific bioinformatics as described previously (Kraushar et al., 2014) to generate lists of functionally related transcripts. RNAseq data are available from National Institutes of Health Gene Expression Omnibus using accession number GSE50809.

Nuclear-cytoplasmic fractionation. Neocortices were dissected in icecold PBS in RNase-free conditions at E13 (4/fractionation), E16 (3/fractionation), and P0 (2/fractionation). Fractionations were performed immediately after in triplicate, using the Protein and RNA Isolation System Kit (Life Technologies \#AM1921). Pelleting of nuclear material was accomplished at $\sim 500 \times g(3000 \mathrm{rpm}$; Sorvall Biofuge Fresco). Fractionated material was then subjected to downstream analysis by Western blot.

Western blot. Western blot analysis was performed as described previously (Kraushar et al., 2014), with NuPAGE 4-morpholinepropanesulfonic acid running buffer (Life Technologies \#NP0001) used for all experiments except laser capture microdissection (LCM) polysome fractionation Western blots, which used NuPAGE MES running buffer (Life Technologies \#NP0002). Primary antibodies were as follows: GAPDH (1:5000, mouse; Millipore \#CB1001-500UG), histone 3 (1:500, rabbit; Cell Signaling Technology \#9715), RPL7 (1:500, rabbit; Abcam \#ab72550), RPL34 (1:500, rabbit; Abcam \#ab129394), RPL10 (1:500, rabbit; Sigma-Aldrich \#HPA011311), TLE4 (1:250, mouse; Santa Cruz Biotechnology \#sc13377), PAX6 (1:250, rabbit; Covance \#PRB278P), SATB2 (1:250, mouse; Abcam \#ab51502), WNT3 (1:100; goat; LifeSpan BioSciences \#LS-B3241), and FOXP2 (1:500, goat; Santa Cruz Biotechnology \#sc21069). Analysis of total neocortical R-protein levels across development was performed with $n \geq 4$ neocortices, $\geq 2$ fractionations/ condition. Anterior versus posterior R-protein levels included $n=4$ neocortices, 2 fractionations/condition. WT versus $W n t 3-\mathrm{cKO}$ total and anterior/posterior neocortical R-protein levels included $n \geq 4$ neocortices, $\geq 2$ fractionations/condition. Western blots were quantified as described previously (Kraushar et al., 2014).

Quantitative real-time PCR. RNA was isolated with TRIzol LS reagent (Life Technologies \#10296), and quantitative real-time PCR (qRT-PCR) was performed and analyzed as described previously (Kraushar et al., 2014). Life Technologies Taqman probes were as follows: $18 \mathrm{~S}$ rRNA (Mm03928990_g1), Foxp2 (Mm00475031_m1), Apc (Mm00545877_m1), luciferase (Mr03987587_mr), Gapdh (Mm99999915_g1). Fractions corresponding to the A260 total RNA absorbance curves monitored during fractionation (Fig. $1 A$ ) were as follows: free (1-3), 40S-60S (4-5), $80 \mathrm{~S}$ (6-7), light polysomes (8-9), heavy polysomes (10-13). $18 \mathrm{~S}$ rRNA measurement in WT anterior versus posterior neocortices included $n=4$ neocortices, 2 fractionations/condition in duplicate. Foxp2 and Apc mRNAs were measured in $n=6-13$ neocortices, $1-2$ fractionations/ condition in duplicate. RNA isolated from total neocortical lysates and in utero electroporation (IUEP) slice cultures were pretreated with the Turbo DNase kit (Life Technologies \#AM1907) before qRTPCR analysis.

LCM coupled to polysome fractionation method. E16 and P0 whole brains were dissected in ice-cold PBS, then flash frozen. Frozen brains were sectioned on a cryostat (Leica CM1900) at $-25^{\circ} \mathrm{C}$ in $60 \mu \mathrm{m}$ sections corresponding to the rostrocaudal sensorimotor neocortex regions denoted in Figure 2B. Sections were mounted on Molecular Machines \& Industries (MMI) MembraneSlides RNase free (\#50102), then fixed in $100 \%$ ethanol for $1 \mathrm{~min}$ at room temperature if subsequent analysis was for protein, or kept cold on dry ice if subsequent analysis was for RNA. LCM was performed using the MMI SmartCut Plus System with Olympus CKX41 microscope and MMI Cell Tools v3.35 software, isolating the

$\leftarrow$

(Figure legend continued.) $\quad \boldsymbol{E}$, Western blot analysis of nuclear-cytoplasmic fractionations from E13, E16, and P0 total neocortical lysates for R-protein subcellular distribution. Confirmation of nuclear-cytoplasmic separation by histone 3 (H3) and GAPDH, respectively. $F$, Western blot analysis of E13, E16, and P0 total neocortex gradient fractionated lysates for R-protein distribution in 40S-60S-80S and polysomes. G, Quantification of $\boldsymbol{F}$ (multivariate ANOVA, followed by ANOVA and then Tukey's HSD post hoc, $p<0.05$ ). regions outlined in Figure $2 B, C$. LCM for subsequent RNA analysis was performed in $\leq 20 \mathrm{~min} / \mathrm{slide}$ to preserve the integrity of RNA. Analysis of polysome fractionations by qRT-PCR included $\geq 10$ brains/layer, or $\geq 40$ brains/layer for Western blot analysis. Collected LCM layers were pooled into tubes with ice-cold polysome extraction buffer, which was subjected to sucrose density ultracentrifugation and fractionation as described previously (Kraushar et al., 2014).

Cell culture. N2a cells were cultured in DMEM (Invitrogen \#31053028) supplemented with 10\% FBS (Sigma-Aldrich \#F6178), $20 \mathrm{~mm}$ HEPES (Invitrogen \#15630-080), sodium pyruvate (Invitrogen \#11360070), glutamax (Invitrogen \#35050-061), and penicillin/streptomycin (Cellgro \#30-001-C1). Primary neuronal cultures from E13 dissociated mouse neocortices were prepared and cultured on glass coverslips as described previously (DeBoer et al., 2014). All cells were cultured at $37^{\circ} \mathrm{C}$ in $5 \% \mathrm{CO}_{2}$. Cells were split into three experimental groups: (1) mock treated (base media only), (2) treated with $100 \mathrm{ng} / \mathrm{ml}$ recombinant WNT3 (Abnova \#H00007473-P01), or (3) $100 \mathrm{ng} / \mathrm{ml}$ both WNT3 and SFRP1 (R\&D Systems \#5396-SF-025) for 48 h. N2a cells were subsequently washed in PBS, treated with $0.01 \mathrm{mg} / \mathrm{ml}$ cyclohexamide (Santa Cruz Biotechnology \#sc-3508A) for $15 \mathrm{~min}$ at $37^{\circ} \mathrm{C}$ in $5 \% \mathrm{CO}_{2}$, then PBS washed, pelleted (900 rpm, 3 min; Beckman Coulter Allegra 21), and resuspended in polysome extraction buffer for downstream fractionation and protein isolation as described previously (Kraushar et al., 2014) in $n=3$ cultures/condition. Primary neuronal cultures were subsequently washed in PBS, then analyzed by immunocytochemistry or by Western blot after resuspension in T-PER (Thermo Scientific \#78510) supplemented with protease inhibitor (Santa Cruz Biotechnology \#sc29131) in $n=3$ cultures/condition.

Plasmids and cloning. The full-length Foxp2-3' UTR was amplified by PCR using the forward primer 5'-TCGCGACTAGTGAACGAACTTG TGACACCTCAGTG-3' and reverse primer $5^{\prime}$-CATATGCGGCCGTGT ACTTCAGAAATGTAACCAACTG-3'. The full-length Foxp1-3'UTR was amplified with the forward primer $5^{\prime}$-TCGCGACTAGTACATGGA GTGAACCTCTGGGC- $3^{\prime}$ and reverse primer $5^{\prime}$-CATATGCGGCC GCATTTAAGAATGCGCTCATGTCAG-3'. Restriction enzyme sites SpeI and EagI were added to each of the forward and reverse primers, respectively, and used for cloning the Foxp2-3'UTRs and Foxp1-3'UTRs downstream of a firefly Luciferase cassette in the pcDNA3.1-Luciferase plasmid, digested with XbaI and EagI. Maxi-preps were performed using a Qiagen kit \#12362.

IUEP. IUEP of E13 mouse sensorimotor neocortices was performed as described previously (Rasin et al., 2007; DeBoer et al., 2014).

Luciferase measurement in E13 neocortical slice cultures. IUEP of E13 mouse sensorimotor neocortices was performed with the Foxp2-3'UTRLuciferase and Foxp1-3'UTR-Luciferase vectors in replicate embryos within separate litters. Four hours post-IUEP, dams were killed, then neocortical dissections were performed in ice-cold HBSS supplemented with $0.5 \%$ D-glucose (American Analytical \#AB00715-00500) and $25 \mathrm{~mm}$ HEPES (Invitrogen \#15630-080). Dissected cortices were then cultured (6-8 per condition) in Neurobasal medium (Invitrogen \#1097077), sodium pyruvate (Invitrogen \#11360-070), 2 mm glutamax (Invitrogen \#35050-061), penicillin/streptomycin (Cellgro \#30-001-C1), and B-27 supplement (Invitrogen \#17504) split into three experimental groups: (1) mock treated (base media only), (2) treated with $100 \mathrm{ng} / \mathrm{ml} \mathrm{recom-}$ binant WNT3 (Abnova \#H00007473-P01), or (3) treated with $100 \mathrm{ng} / \mathrm{ml}$ both WNT3 and SFRP1 (R\&D Systems \#5396-SF-025) for $12 \mathrm{~h}$. Media was aspirated by bulb pipette, washed with $\mathrm{PBS}$, then lysed in passive lysis buffer followed by luciferase measurement with the Dual-Luciferase Reporter Assay System (Promega \#E1910) and TD-20/20 luminometer in triplicate for each condition. Total mRNA was isolated from the same lysates analyzed by luminometer, in equal volumes across conditions with TRIzol LS reagent (Life Technologies \#10296). After pretreatment with the Turbo DNase kit (Life Technologies \#AM1907), total mRNA levels were standardized across conditions with a NanoDrop1000 spectrophotometer (Thermo Scientific) for qRT-PCR. Luciferase relative light units (RLUs) were normalized to Luciferase mRNA levels measured in duplicate qRT-PCRs run in parallel for each condition. Experiments were repeated in 2-4 independent litters, in 2-3 cultures per condition in each litter. 

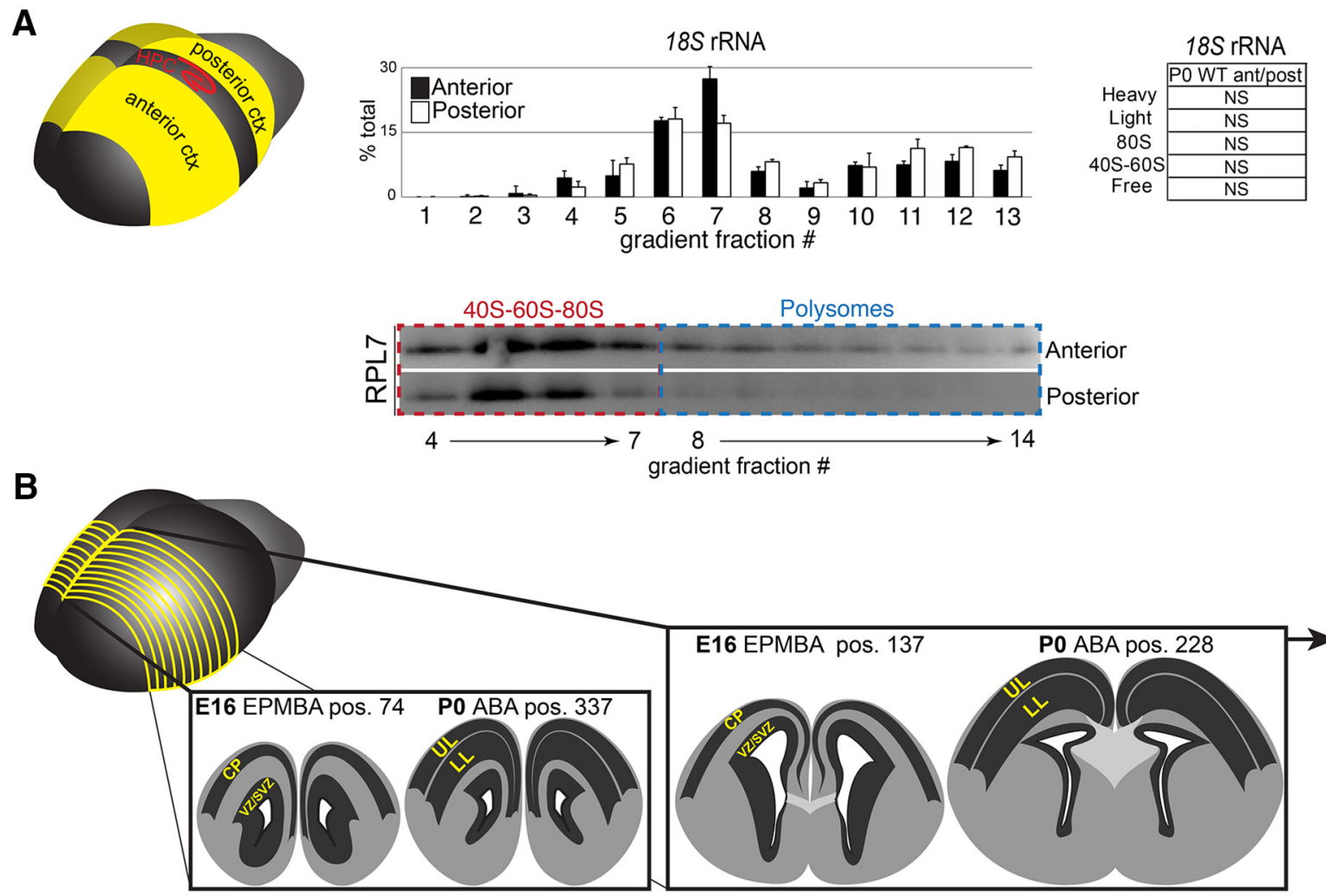

Laser capture microdissection sensorimotor neocortex $\checkmark$ Polysome fractionation R-protein analysis

C

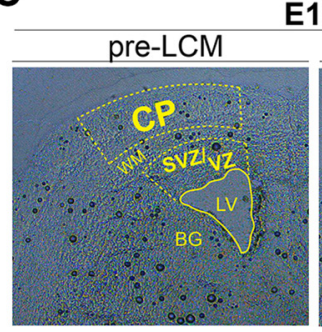

E16
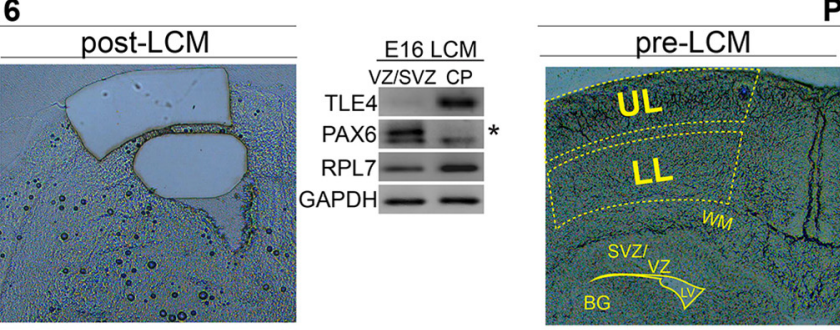

P0
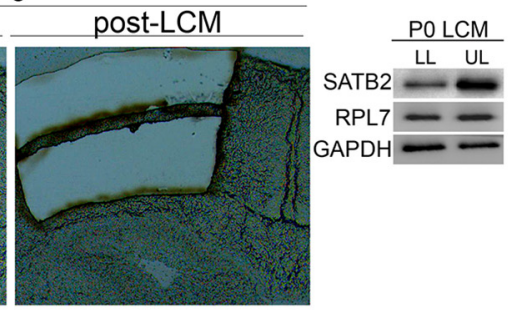

D

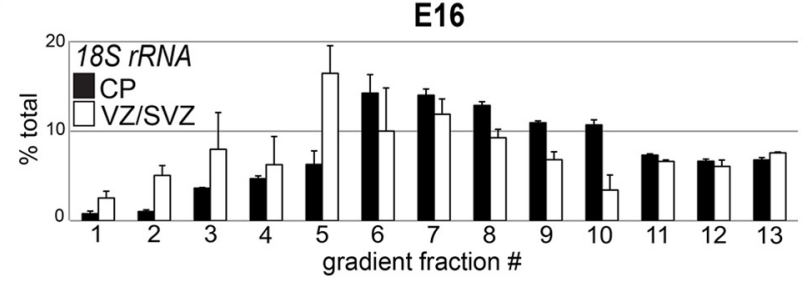

E

\section{E16}

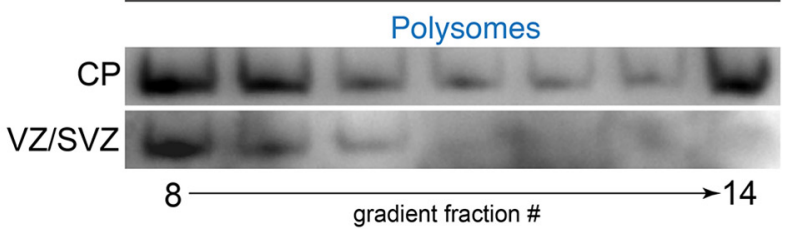

PO

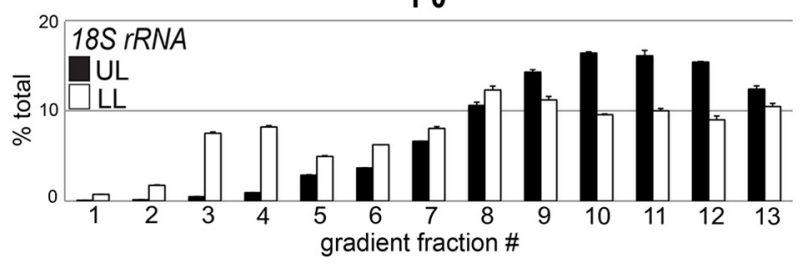

RPL7

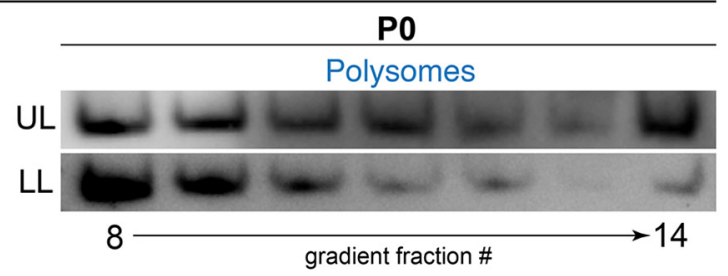

Figure 2. R-protein polysome distribution is regionally and layer specific during neocortical development. $A$, Schematic (left) of anterior sensorimotor versus posterior auditory-visual neocortex subdissection at P0. qRT-PCR analysis of 185 rRNA in anterior versus posterior P0 neocortex gradient fractionations demonstrating equivalent fractionation curves (top right; Bonferroni-corrected $t$ test, $p \geq 0.185$ ). Western blot analysis of RPL7 40S-60S-80S and polysome gradient distribution in the P0 anterior versus posterior neocortex (bottom right). $B$, Schematic of LCM method to analyze the layer-specific R-protein composition in E16 and P0 gradient fractionated sensorimotor neocortices. Coronal sections processed by LCM within the rostrocaudal sensorimotor neocortex boundaries at E16 and P0 are denoted by the Electronic Prenatal Mouse Brain Atlas (EPMBA; http://www.epmba.org) and Allen Brain Atlas (ABA; http://developingmouse.brain-map.org) positions, respectively. C, Representative E16 (left) and PO (right) sensorimotor neocortex coronal sections with LCM regions collected in parallel outlined by dotted yellow lines, and (Figure legend continues.) 
Immunohistochemistry, immunocytochemistry, and imaging. Immunohistochemistry was performed as described previously (Kraushar et al., 2014). Immunocytochemistry was performed similarly on glass coverslips at room temperature, with $1 \mathrm{~h}$ fixation in 4\% PFA w/v in PBS, $1 \mathrm{~h}$ in blocking solution, $1 \mathrm{~h}$ in primary antibody, and $30 \mathrm{~min}$ in secondary antibody before mounting on slides. Primary antibodies were as follows: GFP (1:1000, chicken; Aves Labs \#GFP-1020), WNT3 (1:200, goat; LifeSpan BioSciences \#LS-B3241), MAP2 (1:500, mouse; Sigma-Aldrich \#m4403), L1 (1:500, rat; Millipore \#mab5272), FOXP2 (1:500, goat; Santa Cruz Biotechnology \#sc21069), FOXP1 (1:1000, rabbit; Abcam \#ab16645), APC-CC1 (1:50, mouse; CalBiochem \#OP80-100UG), OLIG2 (1:100, rabbit; IBL-America \#18953), RFP (1:100, rabbit; United States Biological \#R1310-02). DAPI (Roche \#10236276001) was applied 1:5000 for $10 \mathrm{~min}$ at room temperature in all stainings. Slides were imaged using an Olympus FV1000MPE confocal microscope, with $4 \times$ (UPlanFLN), $10 \times(\mathrm{UPlanFLN})$, and $60 \times$ (LUMPlanFLN) objectives. The specificity of the FOXP2 primary antibody was confirmed by immunostaining Foxp2-cKO (French et al., 2007) mouse neocortices (Nex-Cre $\times$ Foxp $\left.2^{\mathrm{fl} / \mathrm{fl}}\right)$.

Quantification of immunocytochemistry. Primary neuronal cultures with FOXP2 and RFP immunocytochemistry were imaged by confocal microscopy at $60 \times$ magnification. Cells from confocal images were quantified by a separate blinded investigator using Neurolucida software for the percentage of FOXP2 RFP-positive neurons among all RFPpositive neurons.

\section{Results}

Dynamic R-protein specificity in neocortical 40S-60S-80S and polysomal fractions at midneurogenesis

Although the translation machinery has been relatively well characterized, few studies have investigated the dynamics of core translation proteins in the developing brain. Ribosome assembly and polysome formation are crucial for proper mRNA translation (Fromont-Racine et al., 2003; Henras et al., 2008; Xue and Barna, 2012; Kraushar et al., 2014). Previously, we showed that ribosomal proteins, mRNA translation, and neuronal specification are regulated by an RNA-binding protein, HuR, and an eIF2 kinase, eIF2ak4, during neocortical development (Kraushar et al., 2014). Thus, we hypothesized that 40S-60S-80S and polysome protein and mRNA components undergo temporal changes in developing neocortices. Our strategy to test this is shown in Figure $1 A$, analyzing $40 \mathrm{~S}-60 \mathrm{~S}-80 \mathrm{~S}$-associated and polysomeassociated proteins and mRNAs from developing neocortices by density gradient fractionation followed by both mass spectrometry and RNAseq, respectively. Representative polysome fractionation curves for the conditions and stages analyzed are presented.

We first isolated 40S-60S-80S and polysome protein components from WT mouse neocortices at E13, E16, and P0 as described previously (Kraushar et al., 2014). We then conducted an unbiased analysis of protein changes in 40S-60S-80S and polysomes by mass spectrometry on combined fractions representing these complexes (Fig. 1A). Inputs were standardized across developmental stages for volume and total protein content. Mass spectrometry peaks were subjected to MudPIT (Washburn et al., 2001) and statistical analysis with Fisher exact tests (potential candidates had $p<0.05$ ). KEGG analysis revealed that most of the proteins with changing levels in 40S-60S-80S and polysome

$\leftarrow$

(Figurelegend continued.) corresponding Western blot measurement for layer-specific markers (SATB2, TLE4, PAX6) and total RPL7 levels at right. D, qRT-PCR analysis of 185 rRNA levels in gradient fractionations of E16 and PO LCM isolated layers from inputs in $\boldsymbol{C}$. $\boldsymbol{E}$, Western blot analysis of RPL7 polysome specificity in E16 VZ/SVZs versus CP on left, and P0 LLs versus ULs on right. complexes were R-proteins associated with $60 \mathrm{~S}$ and/or $40 \mathrm{~S}$ subunits (Fig. 1B). Further analysis showed that changes in R-protein levels occurring predominantly in the early-neurogenic to midneurogenic transition were found to be more significant when we compared E13 to E16 and E13 to P0 stages, but less significant than when we compared E16 to P0 stages. Between E13 and E16, 35 RPLs and 26 RPSs changed in the 40S-60S-80S, and 28 RPLs and 23 RPSs changed in polysomes. These findings suggest that a significant alteration of neocortical translation machinery occurs in the E13-E16 midneurogenic period.

The incorporation of R-proteins into $40 \mathrm{~S}$ and $60 \mathrm{~S}$ ribosomal subunits along with rRNAs occurs in the nucleus before 40S-60S$80 \mathrm{~S}$ and polysome complex assembly in the cytoplasm (FromontRacine et al., 2003; Henras et al., 2008; Fig. 1C). Therefore, we assessed temporal changes in the total levels and subcellular locations of RPL7, which was identified as an R-protein with changing levels in 40S-60S-80S and polysomes, compared with RPL34 with unchanging levels. Furthermore, the presence of RPL7 in neocortical polysomes was previously shown to be regulated by HuR and eIF2ak4 (Kraushar et al., 2014). Western blot analysis detected a significant decrease in total levels of both R-proteins during development (Fig. 1D). This decrease was in contrast to higher RPL7 polysomal levels measured by mass spectrometry at E16 and P0. Therefore, there may be a discrepancy between overall R-protein levels and their association with polysomal fractions in the cytoplasm.

We next assessed the nuclear and cytoplasmic distribution of R-proteins during neocortical development by subcellular fractionation followed by Western blotting. The results showed a cytoplasmic enrichment of RPL7 and RPL10 throughout development, which mimicked the distribution of the control RPL34 (Fig. 1E). These findings suggest that R-proteins are consistently and predominantly maintained in the cytoplasm, where regulation of their incorporation into ribosomal complexes may be observed in 40S-60S-80S and polysomal fractions.

To confirm the mass spectrometry results, we performed quantitative Western blotting for RPL7 and RPL34 in density gradient fractionated neocortices at E13, E16, and P0. Samples were standardized across developmental stages for volume and total RNA content. We found a significant shift of RPL7 from the 40S-60S-80S to polysome fractions during development (Fig. $1 F, G)$. This is in agreement with mass spectrometry data showing that RPL7 levels change in both 40S-60S-80S and polysomes. In contrast, the presence of RPL34 in polysomes was consistently low. We also measured the distribution of RPL10, which has been recently implicated in the etiology of a human ribosomopathy associated with microcephaly, growth retardation, and seizures (Brooks et al., 2014). In contrast to RPL7, RPL10 was characterized by early enrichment in polysomes that decreased by E16 and $\mathrm{P} 0$, thus indicating that R-proteins can both enter and exit polysomes during development. Our dynamic findings are in parallel with stable polysomes monitored during fractionation at each stage (Fig. 1A, fractionation curves; not shown for $18 \mathrm{~S}$ rRNA). Together, these findings indicate that the composition of R-proteins in 40S-60S-80S and polysomes is temporally specific in the neocortex, with R-protein shifts beginning within midneurogenic E13-E16 and maturing by $\mathrm{P} 0$.

\section{R-protein composition in neocortical 40S-60S-80S and polysomal complexes is regionally specific}

Since neocortical development occurs in both spatial and temporal dimensions as described above, we next investigated whether the R-protein composition of 40S-60S-80S and polysomal com- 
plexes was specific in different neocortical regions. First, we isolated the mouse anterior sensorimotor and posterior auditoryvisual neocortex at P0 (Fig. 2A, left schematic) when R-protein shifts are more mature. The hippocampus was used as a rostrocaudal anatomical boundary separating these two structures for dissection. Anterior and posterior neocortices were fractionated, and qRT-PCR analysis of $18 S$ rRNA confirmed that both regions contain similar polysome profiles (Fig. $2 A$, top right). Western blot analysis detected an enrichment of RPL7 specifically in polysomes of the $\mathrm{P} 0$ anterior neocortex compared with posterior neocortex (Fig. 2A, bottom right). This result indicates that different neocortical regions may contain unique R-protein profiles.

To analyze R-protein specificity in different anterior neocortical layers, we developed an LCM method coupled to polysome fractionation and R-protein measurement (Fig. 2B). Brains from $\mathrm{E} 16$ and $\mathrm{P} 0$ animals were flash frozen and sections corresponding to the anterior sensorimotor neocortex were collected (rostrocaudal levels annotated). The E16 LCM-isolated ventricular/subventricular zones (VZs/SVZs) predominantly contained NSC progenitors, whereas the cortical plate $(\mathrm{CP})$ predominantly contained subcortically projecting postmitotic differentiating neurons (Fig. 2C, left). The P0 LCM-isolated lower layers (LLs) contained subcortically projecting differentiating neurons, and the upper layers (ULs) contained intracortically projecting differentiating neurons (Fig. 2C, right). Western blot analysis of polysome inputs confirmed successful isolation of molecularly distinct layers.

Polysome fractionation followed by $18 S$ rRNA qRT-PCR confirmed polysome curves in fractionations from isolated regions at both E16 and P0 (Fig. 2D). Western blot analysis revealed that RPL7 was highly enriched in heavy polysome fractions of the E16 $\mathrm{CP}$ compared with that of the E16 VZs/SVZs (Fig. 2E, left). The presence of RPL7 in polysomes was persistent in P0 LL and UL postmitotic neurons. However, RPL7 was appreciably more enriched in polysomes of UL neurons (Fig. 2E, right). Enrichment of RPL7 in UL polysomes may account for the continued trend toward RPL7-positive polysomes measured in total neocortex at E16-P0 (Fig. $1 F, G$ ), as UL neurons are born later than LL neurons. These results indicate that neural progenitor and differentiating neuron subtypes from the anterior sensorimotor neocortical subregion at E16 contain distinct R-protein compositions in polysomes. The shift of RPL7 into polysomes of differentiating neurons at E16 may constitute a response to a timed signal occurring during midneurogenesis.

\section{Thalamic WNT3 regulates R-protein composition in neocortical polysomes}

Our results indicate that the positioning of R-proteins in polysomes is spatiotemporally regulated in the developing neocortex, beginning between E13 and E16. During this midneurogenic period, ascending thalamocortical axons invade the neocortex at $\sim$ E15 (López-Bendito and Molnár, 2003) and have been implicated in regional and neuronal differentiation (López-Bendito and Molnár, 2003; O'Leary et al., 2007; Fig. 3A). Therefore, we hypothesized that R-protein dynamics in polysomes of developing neocortical cells may be regulated by temporal signals originating from the thalamus.

To identify candidate signals originating from thalamocortical inputs at midneurogenesis, we performed microarray analysis of the thalamus isolated at E15 and E18 and cross-correlated with microarrays from the age-matched neocortex (DeBoer et al., 2013). Bioinformatics analysis focused on mRNAs encoding proteins that were highly enriched in thalamus, but low or absent in the age-matched neocortex. Wnt3, a secreted morphogen, was the most highly upregulated transcript in the thalamus compared with the neocortex (data not shown). Therefore, we targeted WNT3 as a potential temporal signal arriving from the thalamus to the neocortex at E15-E16. Wnt3 qRT-PCR analysis confirmed our microarray data, showing that Wnt3 expression was highly upregulated specifically in the thalamus at E15, and persists until E18 (Fig. 3B). Next, we analyzed Wnt3-Gfp transgenic mice (Gong et al., 2003) to confirm that WNT3-GFP-expressing cells are absent from the cortex, present in the thalamus, and project GFP-positive thalamocortical axons to the developing neocortex at E15 (Fig. 3C). WNT3 immunohistochemistry showed secreted WNT3 accumulation between the neocortical VZ and deep layers of the $\mathrm{CP}$, where thalamocortical axons accumulate starting at E15 (López-Bendito and Molnár, 2003) and are continuously persistent to E18 (Fig. 3D). These results suggest that thalamocortical axons secrete the thalamic morphogen WNT3 into the developing neocortex at E15. Therefore, we hypothesized that the timed thalamic secretion of WNT3 may regulate spatiotemporal changes in neocortical translation machinery.

To test whether thalamic WNT3 regulates R-protein specificity of neocortical polysomes, we generated Wnt3-cKO mice by crossing Wnt $3^{\mathrm{f} / \mathrm{fl}}$ mice (Barrow et al., 2003) to the thalamusexpressing Cre transgenic line, Kcnc2-Cre (Anderson et al., 2005). Thalamic nuclei expressing Kcnc2 (Fig. 3E, inset in situ hybridization) were confirmed to project into the neocortex by imaging Kcnc2-Cre/Gfp mouse neocortices at E16 (Fig. 3E) when R-protein changes were first observed (Fig. 1), with GFP-positive projections persistent to P0 (data not shown). WNT3 depletion in thalamic Kcnc2-Cre/Wnt3 cKOs was confirmed by Western blot (Fig. $3 F$ ). Then, we performed an unbiased screen for $\mathrm{R}$-protein changes in 40S-60S-80S and polysomal complexes in P0 Wnt3-cKO versus WT neocortices by fractionation coupled to mass spectrometry (Fig. 1A). KEGG bioinformatics analysis showed that the absence of thalamic WNT3 only affected a subset of developmentally shifting polysomal R-proteins, including RPL7. Wnt 3 cKO disrupted a total of 5 RPL and 15 RPS R-proteins. Of the R-proteins affected by Wnt 3 cKO, 4 of 5 RPLs and 15 of 15 RPSs were independently identified as developmentally changing levels in 40S-60S-80S and/or polysomes between WT E13 and E16. Western blot analysis of P0 Wnt3-cKO versus WT total neocortices and nuclear-cytoplasmic fractionated neocortices (Fig. $3 F$ ) indicated that the overall levels of RPL7 identified by mass spectrometry did not change. These results suggest that conditional deletion of thalamic WNT3 could specifically affect R-proteins in neocortical polysomes.

To test this possibility, P0 WT and Wnt3-cKO total neocortices were polysome fractionated. Polysome curves monitored during fractionation confirmed the presence of intact polysome profiles in $W n t 3 \mathrm{cKOs}$ (Fig. $1 \mathrm{~A}$, fractionation curves). However, quantitative Western blot analysis revealed that RPL7 was depleted from Wnt3-cKO neocortical polysomes compared with WT controls at $\mathrm{P} 0$ (Fig. $3 G$ ). These results indicate that thalamic WNT3 regulates neocortical polysome protein specificity, possibly influencing regional differences in polysome R-protein expression.

To test whether WNT3 regulation of polysome protein specificity is regionally specific, we analyzed polysome-fractionated anterior and posterior neocortices from $W n+3$ cKOs versus WT at P0. Western blot analysis showed that RPL7 was depleted in Wnt3-cKO anterior neocortical polysomes, a shift toward the WT posterior neocortical composition (Fig. 3H). In contrast, the RPL7 distribution in posterior Wnt3-cKO neocortices was unchanged. These re- 
A
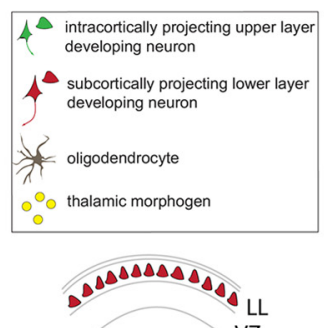

ttt E13 nctx

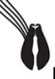

E13 thal

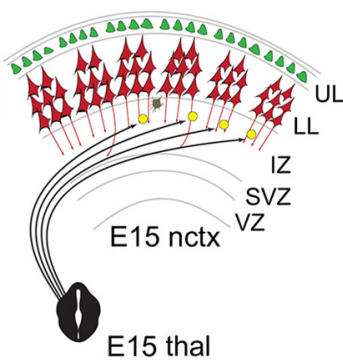

D

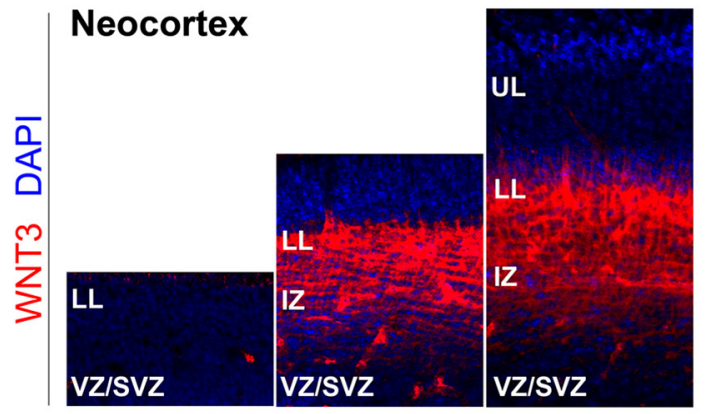

E13
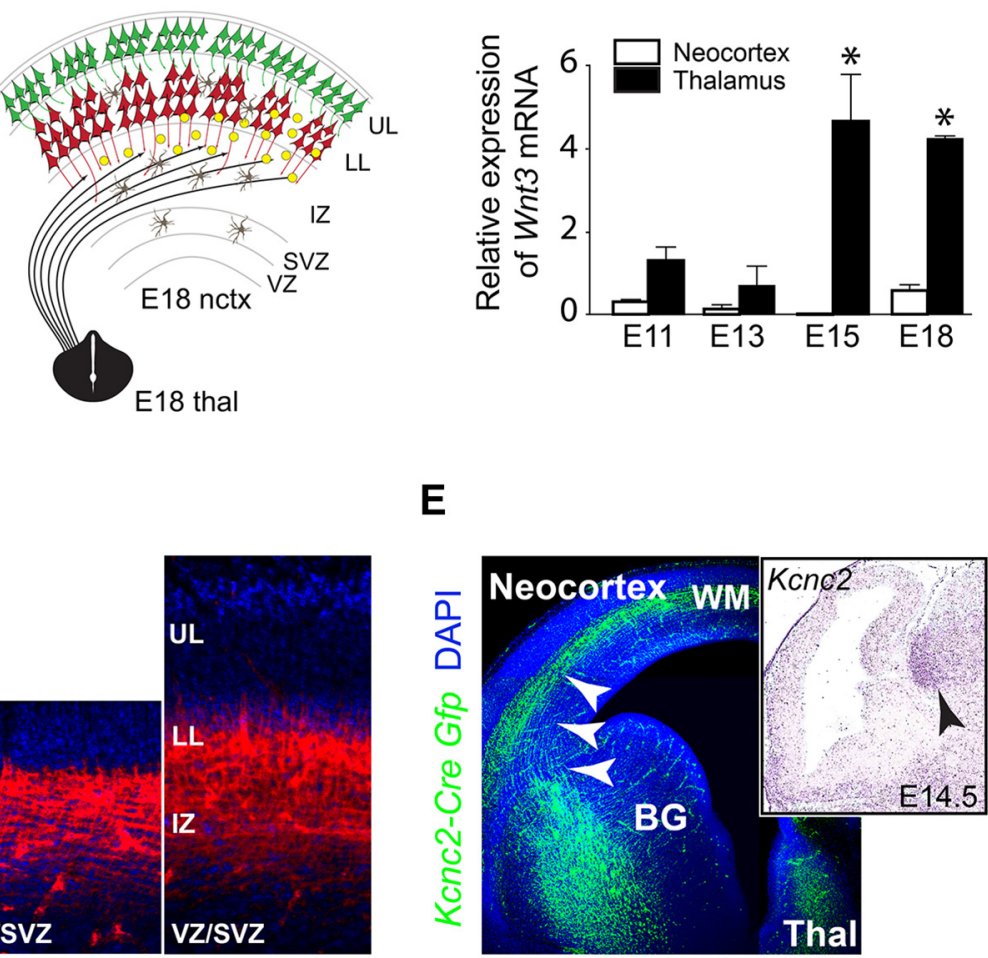

E16

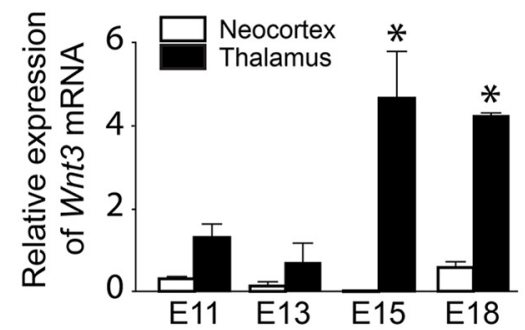

E

B

E18
E15

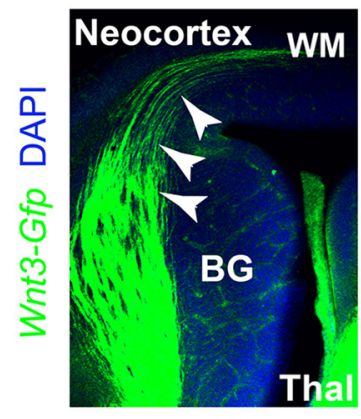

E15

G

$\mathbf{F}$

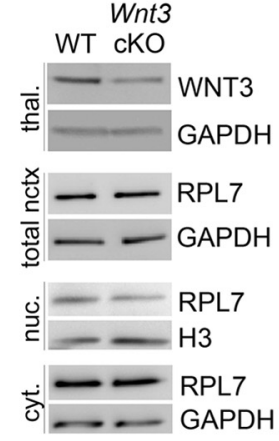

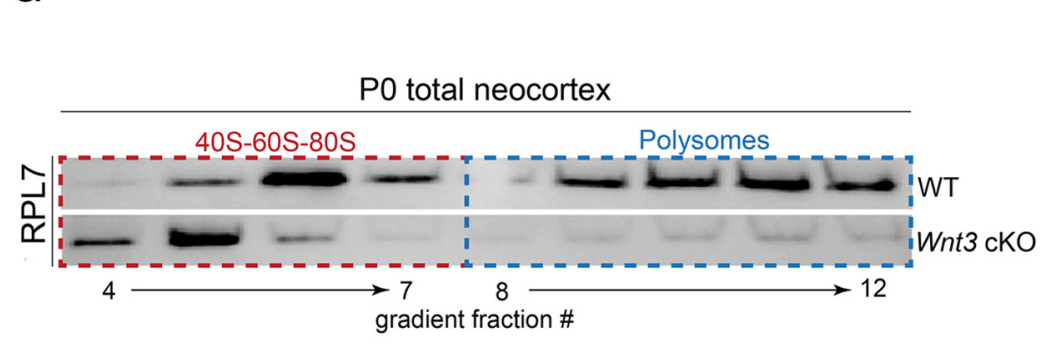

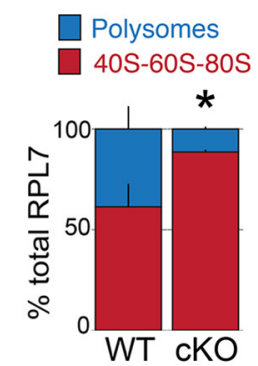

H

$\mathrm{PO}$ anterior neocortex

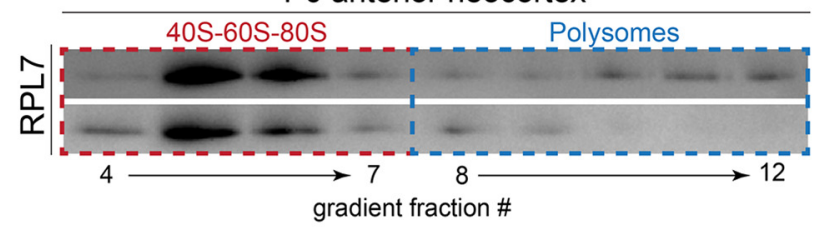

P0 posterior neocortex

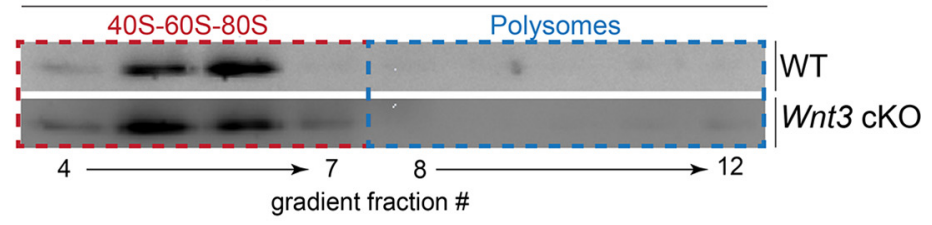

I

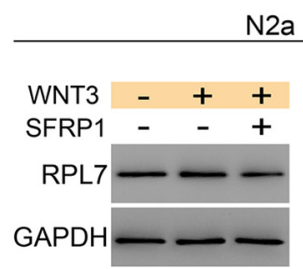

N2a cells

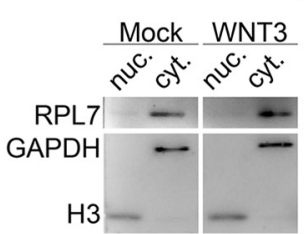

$\mathbf{J}$

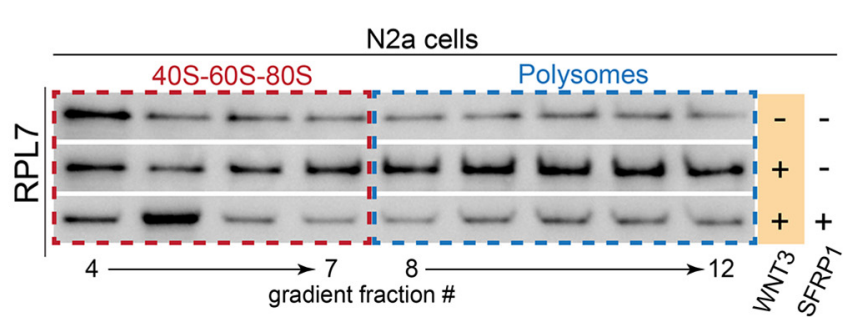

Figure 3. Timed thalamocortical WNT3 secretion regulates the R-protein composition of polysomes in the developing sensorimotor neocortex. $A$, Schematic of the spatiotemporal innervation of the neocortex beginning at midneurogenesis E15 by thalamic axons. $\boldsymbol{B}, W n t 3 \mathrm{qRT}-\mathrm{PCR}$ of the developing neocortex and thalamus $(t$ test, $p<0.05)$. $\boldsymbol{C}$, Immunohistochemistry and coronal imaging of Wnt3-Gfp mouse neocortical and subcortical structures at E15. GFP (green) in thalamus and thalamocortical axons reaching the neocortex (arrowheads; DAPI in blue). D, WNT3 immunohistochemistry (red) in coronal sections of the developing neocortex. LLs, ULs, intermediate zone (IZ) white matter, and VZ/SVZs (DAPI in blue). E, (Figure legend continues.) 
sults suggest that depletion of thalamic WNT3 by Kcnc2-Cre has a specific effect on anterior neocortical polysomes.

To confirm the specificity of the effect of WNT3 on neuronal polysomes, we treated a neurobalstoma cell line $(\mathrm{N} 2 \mathrm{a})$ with either mock, WNT3, or WNT3 plus WNT-signaling inhibitor SFRP1 $(100 \mathrm{ng} / \mathrm{ml}$ each) for $48 \mathrm{~h}$. Western blot analysis of total (Fig. 3I, left) and nuclear-cytoplasmic-fractionated (Fig. 3I, right) RPL7 levels showed no differences between the three culture conditions. In contrast, Western blot analysis of polysomefractionated cultures showed that N2a cells treated with WNT3 had higher levels of RPL7-positive polysomes, whereas the addition SFRP1 redistributed the levels of RPL7-positive polysomes to mock levels (Fig. $3 J$ ). Collectively, these results indicate that thalamocortical WNT3 secretion regulates the spatiotemporal R-protein specificity of polysomes in the developing neocortex. This midneurogenic signaling mechanism may act in concert with other mRNA translation regulation occurring throughout neocortical development (DeBoer et al., 2013; Kraushar et al., 2014). Timed changes to components of ribosomal complexes may correspond to the temporal regulation of mRNA translation.

\section{Functionally related mRNAs dynamically associate with actively translating polysomes in the developing neocortex} Temporal changes in ribosome composition should correspond to the temporal regulation of mRNA translation (Xue and Barna, 2012). To identify temporal changes in mRNA translation during neocortical development, we first performed sucrose density gradient ultracentrifugation and fractionation of WT mouse E13 and P0 neocortices. Inputs were standardized across developmental stages for volume and total RNA content. Then, we used an unbiased screen using RNAseq to compare levels of total mRNA, mRNA associated with 40S-60S-80S cytoplasmic fractions, and mRNA associated with polysomal cytoplasmic fractions at E13 and P0 (Fig. 1A), as described previously (Kraushar et al., 2014). As expected, numerous mRNAs were differentially expressed in total levels, with significantly higher expression at E13 (Fig. $4 A$, yellow) or at P0 (Fig. $4 A$, green), suggesting transcriptional or mRNA stability control. However, the total levels of many mRNAs did not change significantly between E13 and P0 (Fig. $4 A$, black), which may include mRNAs that are regulated specifically at the translational level.

To identify genes that were regulated specifically at the translational level, we selected genes with unchanged total transcript levels between E13 and P0, but with different levels in the 40S$60 \mathrm{~S}-80 \mathrm{~S}$ or polysomal fractions (Fig. $4 B$ ). A total of 23,182 genes

\section{$\leftarrow$}

(Figure legend continued.) GFP immunohistochemistry (green) in coronal sections of Kcnc2Cre/Gfp transgenic mice at E16. Thalamocortical axons reaching the neocortex are denoted by white arrowheads (DAPI in blue). Kcnc2 in situ hybridization in E14.5 neocortical sagittal sections (inset; from the Eurexpress Database, www.eurexpress.org), with thalamic expression denoted by black arrowhead. F, Western blot analysis of PO Wnt3-cKO vs WT lysates confirming thalamic WNT3 depletion, and levels of RPL7 in total and nuclear-cytoplasmic fractionated neocortices (balanced to H3 and GAPDH). G, Western blot analysis of RPL7 in PO Wnt3-cKO vs WT fractionated total neocortices (left). Quantification of RPL7 40S-60S-80S and polysome distribution (right; Mann-Whitney $U$ test, $p=0.012$ ). $\boldsymbol{H}$, Western blot analysis of RPL7 levels in P0 Wnt3-cKO vs WT anterior sensorimotor and posterior auditory-visual fractionated neocortices. I, Western blot analysis of RPL7 levels in neuronal cell line (N2a) cultures exposed to mock, WNT3, or WNT3 plus SFRP1 inhibitor conditions; total levels (left); and nuclear-cytoplasmic fractionated levels (right) balanced to GAPDH and H3.J, Western blot analysis for RPL7 levels in polysome fractionations of N2a cultures exposed to mock, WNT3, or WNT3 plus SFRP1 inhibitor conditions. were detected: 18,552 transcripts ( $80 \%$ ) showed unchanged total levels between E13 and P0, 470 transcripts differed in the 40S$60 \mathrm{~S}-80 \mathrm{~S}$ fraction, and 223 transcripts differed in the polysome fraction (Fig. 4C). These results suggest that a large number of mRNAs are translationally regulated at the level of the ribosome during neocortical development. These mRNAs may require timed signals to induce shifts between the free, 40S-60S-80S, and polysomal fractions.

To determine whether specific pathways are regulated at the translational level, we performed GO (Ashburner et al., 2000) and KEGG (Kanehisa et al., 2014) analysis of mRNA transcripts with dynamic enrichment in 40S-60S-80S and/or polysomal fractions during development, but unchanged in total mRNA levels (Fig. 4D). The greatest number of mRNAs that were downregulated in polysomes between E13 and P0 encoded proteins involved in translation (GO:0006412; Fig. 4D, left) and ribosome-associated proteins (KEGG:mmu03010; Fig. $4 D$, right). The GO translation group contained several initiation and elongation factors (eIF3F, eIF3G, eIF2B2, eEF1G, eEF1B2), one tRNA ligase (AARS2), one RNA-binding protein (KHSRP), and one initiation kinase (eIF2ak4). Importantly, eIF2ak4 (also known as GCN2) interacts with $\mathrm{HuR}$ to regulate neocortical polysome protein specificity (Kraushar et al., 2014). The group with the greatest number of mRNAs displaying decreased levels in the 40S-60S-80S fraction between E13 and P0 contained transcriptional genes (GO: 0006350; Fig. 4D, left). These findings suggest that mRNAs encoding translation and transcription-associated proteins are the most dynamic in 40S-60S-80S and polysome complexes during neocortical development.

Since we observed both temporal-specific and layer-specific changes to proteins in the ribosomal machinery, we next performed layer-specific bioinformatics analysis (Belgard et al., 2011; Kraushar et al., 2014) to assess whether mRNAs enriched in distinct neocortical layers during development do not change in total mRNA levels, but are also dynamic in 40S-60S-80S and polysomal complexes. Results showed that numerous mRNAs enriched in layers $2-3$ and 5 are regulated by this mechanism (Fig. $4 E$ ), which is consistent with previous findings of layer-specific mRNA regulation by HuR during development (Kraushar et al., 2014). Our temporal-specific, regional-specific, and layerspecific findings suggest that changes in 40S-60S-80S and polysomal complex composition may define spatiotemporal regulation of translation in the developing neocortex, specifying mRNA translation with a timed signal.

\section{Thalamic WNT3 regulates Foxp2 and Apc mRNA translation in the neocortex}

WNT signaling regulates neuronal and oligodendrocyte differentiation (Castelo-Branco et al., 2003; Langseth et al., 2010; Tsai et al., 2012; Lang et al., 2013). GO pathway analysis showed that mRNAs encoding transcription factors promoting layer-specific neuronal differentiation, such as Foxp2 (Tsui et al., 2013), and oligodendrocyte maturation, such as Apc (Jablonska et al., 2012; Lang et al., 2013), were highly regulated developmentally (Fig. $4 D, E)$. To test whether thalamic WNT3 regulates neocortical neuronal and oligodendrocyte differentiation via mRNA translation, we first performed immunohistochemistry analysis of Wnt3-cKO and WT neocortices at P0 (Fig. 5A). We observed no significant differences in expression of the general differentiated neuronal marker MAP2 or axonal marker L1 (Fig. 5A, left). However, thalamic Wnt $3 \mathrm{cKO}$ neocortices had reduced expression of neocortical LL 5-6 marker FOXP2, while the adjacent layer 3-4 marker FOXP1 remained detected (Fig. 5A, middle). FOXP2 ex- 
A

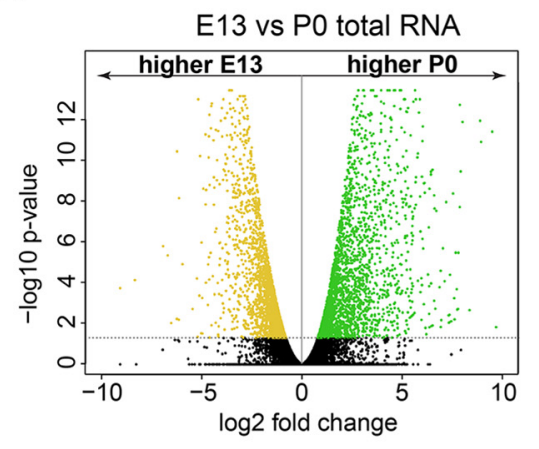

C

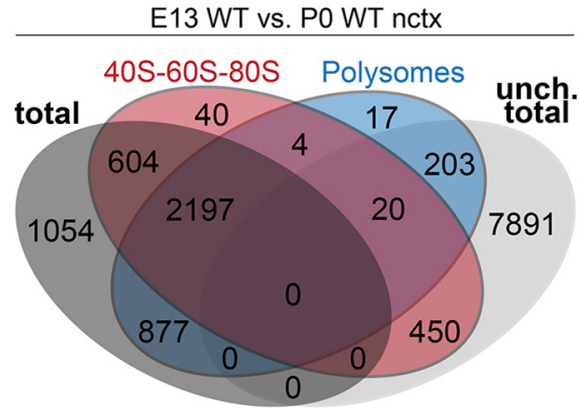

B
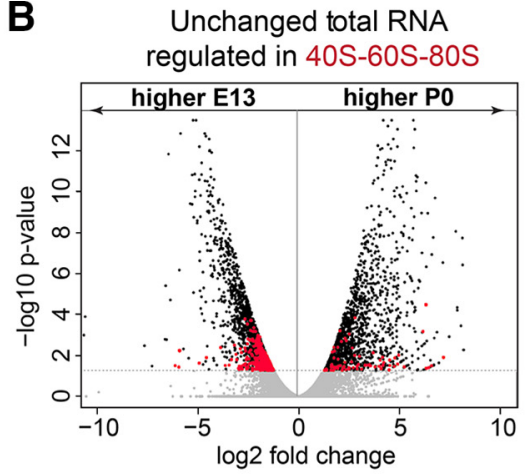

Unchanged total RNA regulated in Polysomes

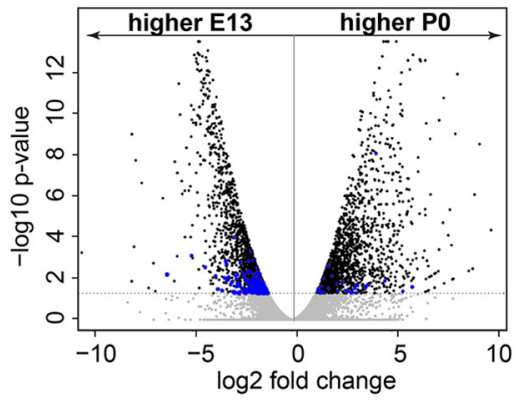

D

Polysome mRNAs higher at E13 than P0 40S-60S-80S mRNAs higher at E13 than P0

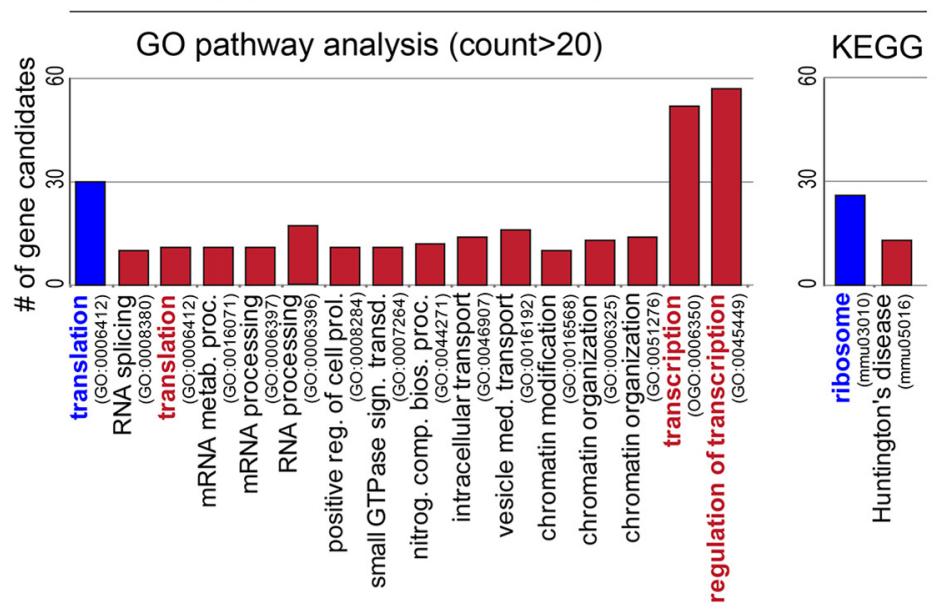

E
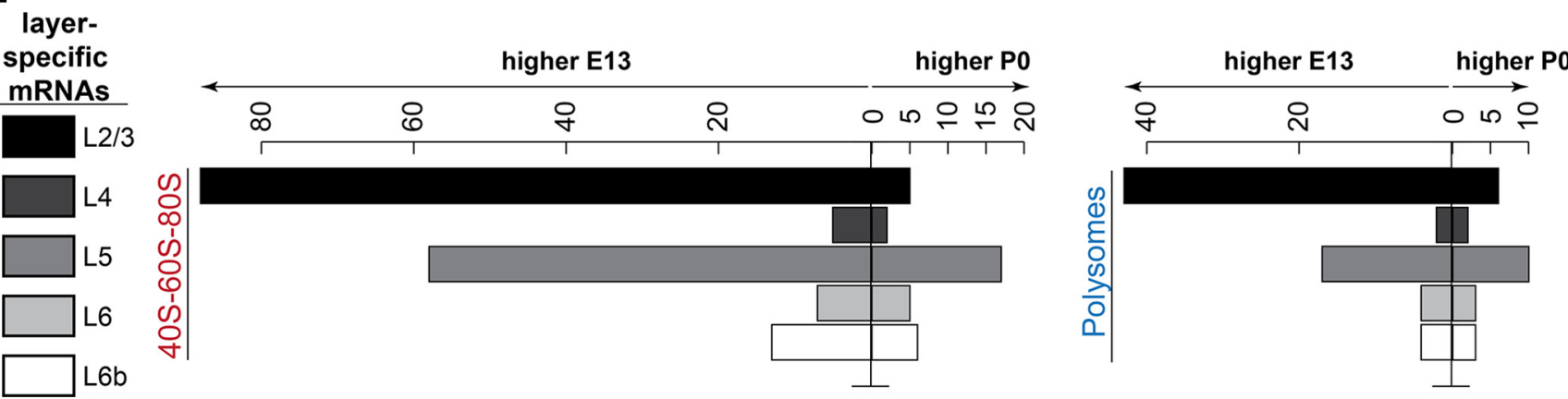

Figure 4. mRNAs temporally regulated in neocortical 40S-605-80S and polysomes are functionally related and layer specific. $A$, Volcano plot showing distinct mRNAs revealed by RNAseq measurement as higher in total neocortical levels at E13 (yellow) or higher at P0 (green). Those not significantly changed $(p>0.05$ ) are shaded black. $\boldsymbol{B}$, Volcano plot showing the distribution of mRNAs measured by RNAseq that are significantly different in 40S-60S-80S-associated (red) or polysome-associated (blue) fractions but unchanged in total levels, compared with those changed in total levels (black) between E13 and P0. C, Venn diagram summary of RNAseq showing the number of mRNAs that changed significantly in total, 40S-60S-80S-associated levels between E13 and P0, and/or polysome-associated levels between $\mathrm{E} 13$ and $\mathrm{P0}$, compared with those unchanged in total levels (false discovery rate, $\leq 5 \%$ ). D, RNAseq G0 (left) and KEGG (right) pathway analysis of mRNAs significantly changed in 40S-60S-80S or polysomes between E13 and P0, but unchanged in total levels. E, Bioinformatics analysis of layer-specific mRNAs dynamic in 40S-60S-80S (left) or polysomal (right) levels, but unchanged in total levels.

pression was maintained in the basal ganglia of Wnt3 cKOs, suggesting the effect is specific to the neocortex where thalamocortical inputs would accumulate. In contrast, we observed premature expression of APC, a marker transiently induced in oligodendrocytes during myelination (Jablonska et al., 2012; Lang et al., 2013), particularly in the CP and likewise in the corpus callosum (Fig. 5A, right). The more general oligodendrocyte progenitor marker OLIG2 was expressed as expected. To rule out the possible influence of any WNT3 originating from within the cor- tex, FOXP2 and APC immunohistochemistry was repeated in Emxl-Cre/Wnt $3^{\mathrm{fl} / \mathrm{fl}}$ mutants with conditional deletion in all neocortical projection neurons and glia in the EMX1 progenitor lineage (Gorski et al., 2002; Katsanou et al., 2009). The distributions and levels of FOXP2 and APC were found to be unchanged in P0 Emx1 cKOs compared with WT (Fig. 5B). These results indicate that thalamic WNT3 promotes the differentiation of deep neocortical layers and suppresses premature oligodendrocyte maturation in developing neocortices. 
A
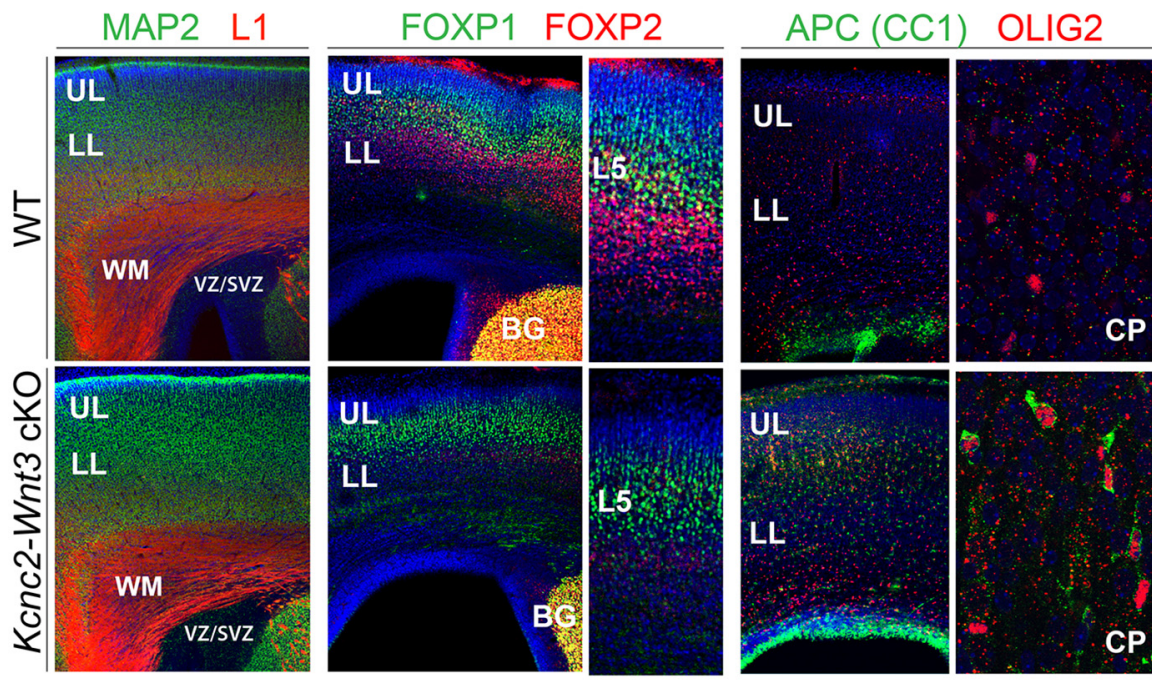

APC (CC1)

B

FOXP2

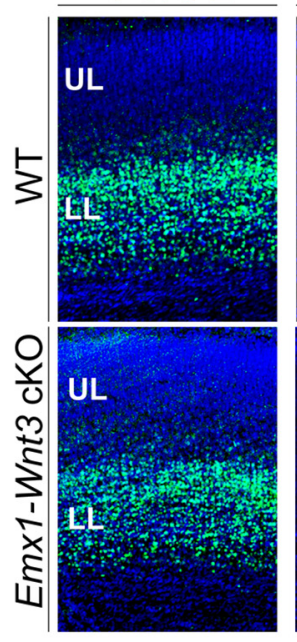

OLIG2

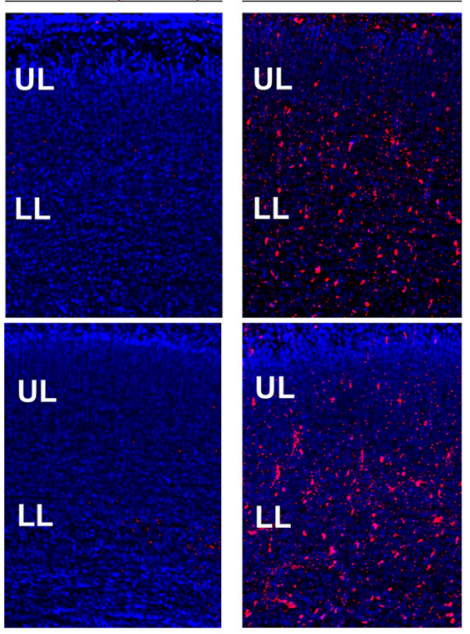

C

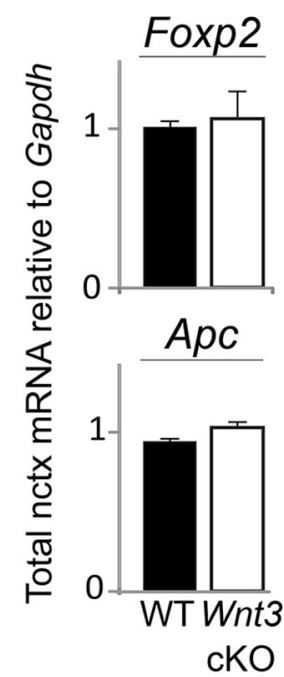

\section{D}
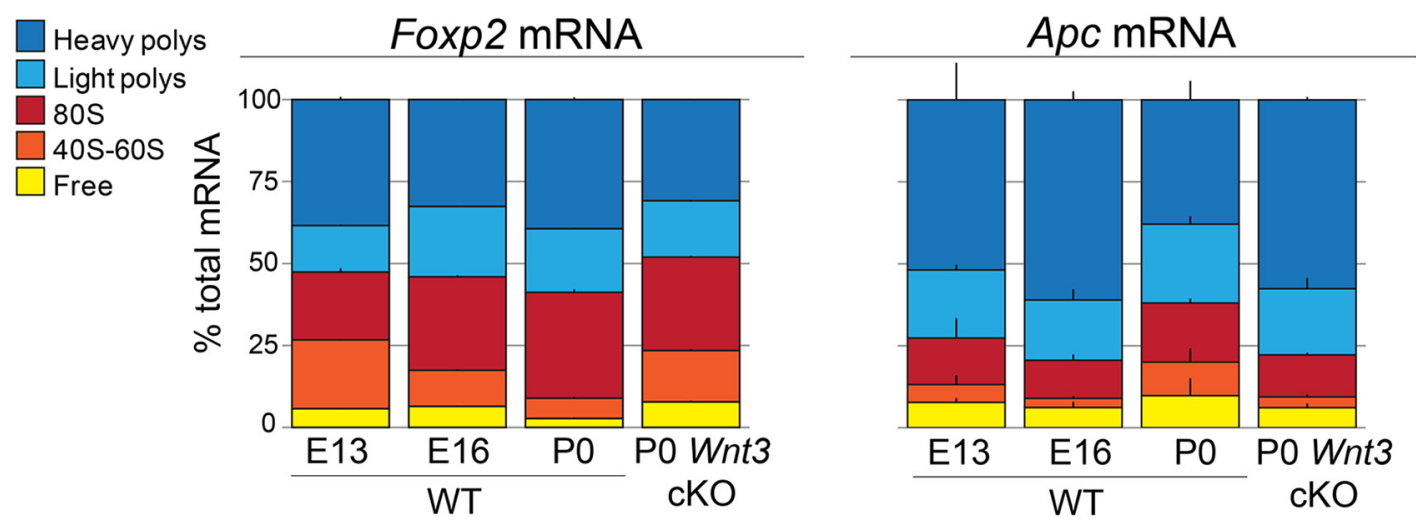

\begin{tabular}{|c|c|c|c|c|c|}
\hline \multirow{2}{*}{ Heavy } & E13/E16 & E13/P0 & E16/P0 & \multicolumn{2}{|c|}{ P0 WT/cKO E16 WT/P0 cKO } \\
\hline & NS & NS & NS & NS & 0.026 \\
\hline Light & 0.025 & 0.008 & NS & 0.017 & 0.027 \\
\hline $80 S$ & NS & 0.022 & NS & NS & NS \\
\hline $40 S-60 S$ & NS & 0.020 & 0.036 & 0.004 & NS \\
\hline Free & NS & NS & 0.021 & 0.011 & NS \\
\hline
\end{tabular}

\begin{tabular}{|c|c|c|c|c|}
\hline E13/E16 & E13/P0 & E16/P0 & P0 WT/cKO & E16 WT/P0 cKO \\
\hline NS & NS & 0.005 & 0.018 & NS \\
\hline NS & NS & NS & NS & NS \\
\hline NS & NS & NS & NS & NS \\
\hline NS & NS & NS & NS & NS \\
\hline NS & NS & NS & NS & NS \\
\hline
\end{tabular}


We next asked whether changes in FOXP2 or APC protein expression in Wnt3-cKO neocortices occur at the transcriptional or translational levels. Total levels of Foxp2 and $A p c$ mRNAs were measured by qRT-PCR, and no significant changes of steadystate mRNA levels were observed between Wnt3-cKO and WT neocortices at P0 (Fig. 5C). However, when we analyzed polysome-fractionated neocortices, Foxp2 mRNA shifted out of polysomes and into 40S-60S fractions in the P0 Wnt $3 \mathrm{cKO}$ compared with WT (Fig. 5D), concordant with a decrease in FOXP2 translation. Changes in Foxp2 mRNA distribution mirrored RNAseq findings for transcription factor mRNAs being regulated in the 40S-60S-80S, and more closely represented the distribution seen earlier in development at WT E16. In contrast, we detected a shift of Apc mRNA into heavy polysomes in P0 $W n t 3$ cKOs, more closely approximating the Apc mRNA distribution at WT E16 (Fig. 5D). This shift would typically be associated with a higher rate of $A p c$ translation and premature APC protein accumulation in oligodendrocytes. Together, these findings suggest that subsets of neocortical mRNAs are regulated at the translational level in response to timed thalamic WNT3 signaling.

\section{WNT3 regulates Foxp 2 translation in the sensorimotor neocortex via its $3^{\prime}$ UTR}

To confirm that WNT3 is sufficient to promote FOXP2 protein expression in neocortical projection neurons, we performed IUEP at E13 of an $R f p$ reporter in the sensorimotor neocortex and prepared primary neuronal cultures (Rasin et al., 2007; DeBoer et al., 2014). Postmitotic differentiating neurons were generated after $3 \mathrm{~d}$ in vitro; then treated with mock, WNT3, or WNT3 plus SFRP1; and analyzed for FOXP2 protein expression after $48 \mathrm{~h}$. Immunohistochemistry analysis showed that WNT3 treatment increased the number of FOXP2 RFP-positive neurons, whereas the addition of SFRP1 abolished this effect (Fig. 6A, imaging left, quantification right). Western blot measurement of FOXP2 protein output in these cultures confirmed the specific effect of WNT3 (Fig. 6B).

The three prime untranslated region ( $3^{\prime}$ UTR) is important for post-transcriptional regulation of gene expression, modulating mRNA association with the ribosome and translation efficiency (Mazumder et al., 2003a). Therefore, we asked whether the specific 3'UTR sequence of Foxp2 mRNA could regulate translation efficiency in response to WNT3 signaling in the developing neocortex at E13, just before thalamic WNT3 secretion. To test this, we cloned the 3'UTR of Foxp2 (protein expression disrupted in Wnt 3 cKO) and Foxp1 (protein expression unchanged in Wnt3 cKO) downstream of a Luciferase reporter (Fig. 6C, left). E13 IUEP with the Foxp2-3'UTR-Luciferase and Foxp1-3'UTRLuciferase constructs was performed in the sensorimotor region.

\section{$\leftarrow$}

Figure 5. Thalamic WNT3 regulates the translation of Foxp2 and Apc in the neocortex. $\boldsymbol{A}$, Immunohistochemistry and coronal imaging of general differentiated neuron marker MAP2 (green), axonal marker L1 (red), differentiated projection neuron markers F0XP1 (green) and FOXP2 (red), and oligodendrocyte markers APC-CC1 (green) and OLIG2 (red) in PO Kcnc2-Wnt3cKO vs WT neocortices ( $4 \times$ left, inset right, DAPI in blue). L5, Layer 5; BG, basal ganglia; CC, corpus callosum. $\boldsymbol{B}$, Immunohistochemistry and coronal imaging of FOXP2 (green), APC (red), and OLIG2 (red) in P0 Emx1-Wnt3-cKO vs WT neocortices (DAPl in blue). C, qRT-PCR analysis of Foxp2 and Apc mRNA total levels in P0 Kcnc2-Wnt3-cKO vs WT neocortices relative to Gapdh. D, qRT-PCR analysis of Foxp2 and Apc mRNA in polysome fractionations of E13, E16, and P0 WT vs PO Kcnc2-Wnt3-cKO neocortices. Quantification of mRNA distribution on top, statistical analysis on bottom, significant comparisons in red (multivariate ANOVA, ANOVA, Games-Howell post hoc, $p<0.05)$.
Four hours later, neocortical slice cultures were prepared and exposed to either mock, WNT3, or WNT3 plus SFRP1 conditions for $12 \mathrm{~h}$, followed by luciferase measurement. Luciferase RLUs were normalized to Luciferase mRNA levels to analyze translation-specific effects (Xue et al., 2015). Results showed that treatment with WNT3 was sufficient to induce an increase in translation via the Foxp2-3'UTR in neocortical slices, while addition of the SFRP1 inhibitor mirrored mock levels (Fig. 6C, right). The response to WNT3 signaling was specific to the Foxp2-3'UTR, since the Foxp1-3'UTR construct was unresponsive. Together, these data indicate that WNT3 can act in developing neocortices via the Foxp2-3'UTR to regulate Foxp2 mRNA translation.

\section{Discussion}

Our study shows that R-proteins differentially associate with 40S$60 \mathrm{~S}-80 \mathrm{~S}$ and polysome complexes during neocortical neurogenesis, with regional and layer specificity. Likewise, mRNA subsets that are unchanged in total levels across development differentially associate with neocortical 40S-60S-80S and polysome complexes in a temporally dependent manner. WNT3 secretion from ingrowing thalamic axons at midneurogenesis spatiotemporally regulates a subset of dynamic R-proteins in the developing neocortex, promoting the association of RPL7 with polysomes. In concert, thalamic WNT3 drives LL specification via translation of Foxp2 mRNA, while inhibiting Apc translation to suppress oligodendrocyte maturation. Thus, timed thalamic morphogen signaling regulates both composition and output of the neocortical translation machinery, specifying distinct neocortical cell types by the specificity of mRNA translation.

We describe the combinatorial composition of R-proteins in polysomes during neocortical development as the "neocortical ribosome signature" (Fig. 7A). Previously, we showed that the neocortical ribosome signature is under intrinsic control by an RNA-binding protein, HuR (Kraushar et al., 2014). We now further show that the neocortical ribosome signature is under extrinsic control by thalamic WNT3 signaling. The canonical WNT signaling pathway regulates a wide range of developmental processes, predominantly through transcriptional regulation (López-Bendito and Molnár, 2003; Machon et al., 2007; Choe et al., 2012). However, similar to our findings, WNT signaling also influences translation by suppressing GSK3-dependent and AMPK-primed phosphorylation of TSC2, which in turn regulates the mammalian target of rapamycin pathway (Inoki et al., 2006). Our study identifies an alternative pathway by which WNT signaling may influence mRNA translation, possibly acting in parallel with regulation at the transcriptional level to fine tune control of gene expression. Mechanisms controlling timed mRNA translation may further act in concert with other posttranscriptional regulators operating throughout development, such as HuR, to influence the neocortical ribosome signature. Similar to HuR, thalamic WNT3 shifts neocortical R-proteins and mRNAs into and out of polysomes, and also affects the maturation of developing neocortical neurons and oligodendrocytes (Fig. 7B). Therefore, thalamocortical innervation and arrival of WNT3 is essential for normal neocortical development and spatiotemporal regulation of mRNA translation.

Thalamic morphogen signaling and a dynamic ribosome signature may function to differentially regulate the specification of regional and/or layer-specific subtypes of neocortical projection neurons and glia via the translation of subsets of mRNAs. For example, we observed that conditional deletion of thalamic WNT3 affected the FOXP2-positive layer 5-6 subpopulation of 
A

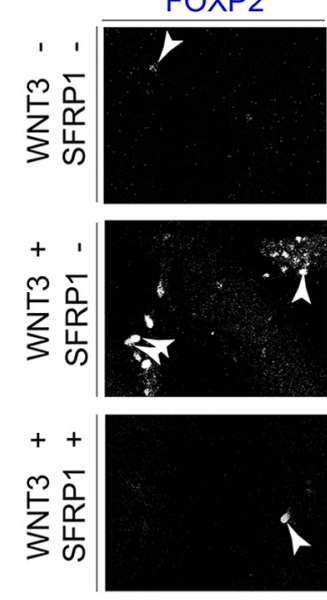

RFP
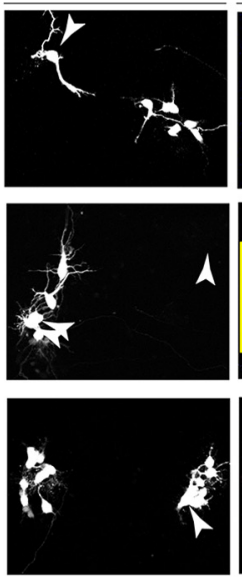
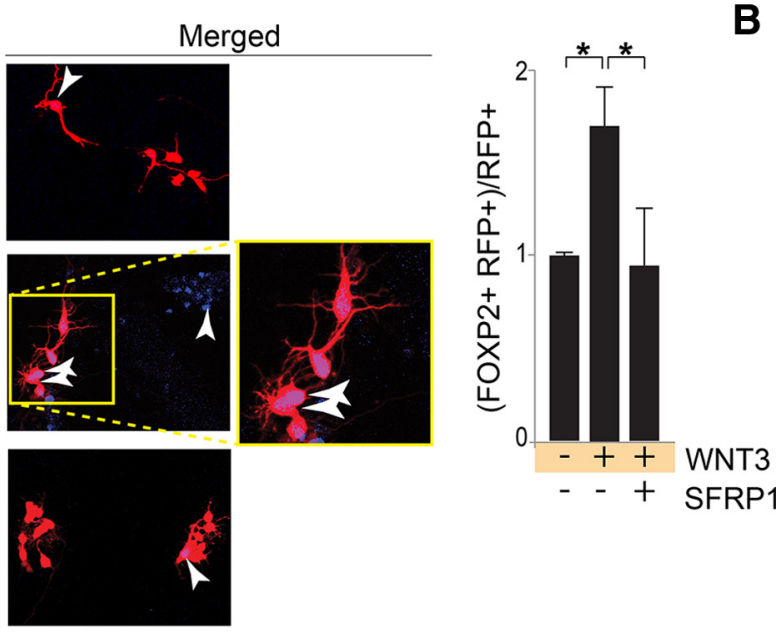

B

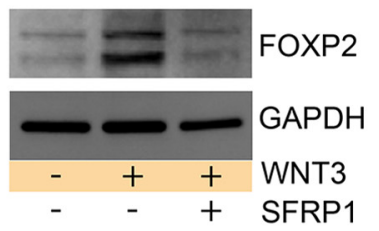

\section{C}
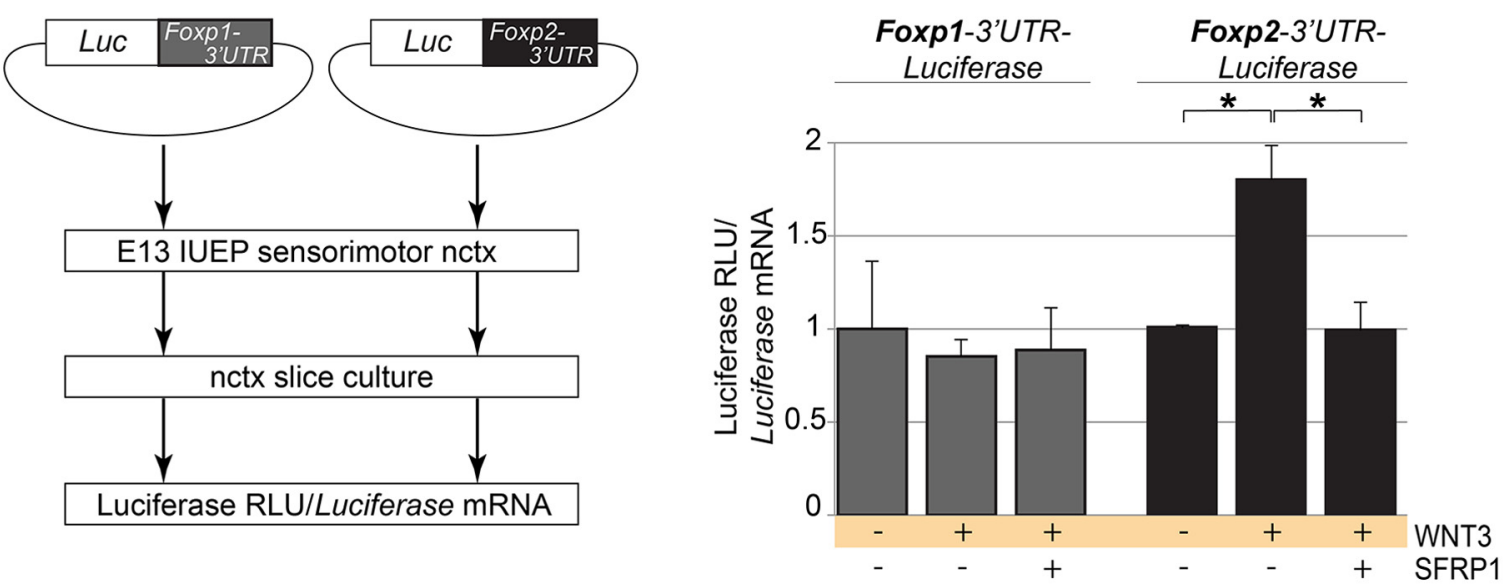

Figure 6. WNT3 regulates Foxp2 mRNA translation via its 3'UTR. A, FOXP2 (blue) and RFP (red) immunocytochemistry in primary neocortical neuronal cultures after Rfp IUEP at E13 in the sensorimotor neocortex, then cultured in mock, WNT3, or WNT3 plus SFRP1 inhibitor conditions for $48 \mathrm{~h}$ (images and inset on left; arrowheads indicate F0XP2 RFP-positive neurons). Quantification (right) of the fold change in the percentage of F0XP2 RFP-positive neurons among all RFP-positive neurons when normalized to mock levels ( $t$ test, $p<0.05$ ). $\boldsymbol{B}$, Western blot analysis of F0XP2 protein expression in primary neuronal cultures exposed to mock, WNT3, or WNT3 plus SFRP1 inhibitor conditions. C, Schematic (left) and quantification (right) of luciferase measurement in E13 neocortex slices IUEP with Foxp 1-3' UTR-Luciferase or Foxp2-3' UTR-Luciferase constructs in the sensorimotor region, then cultured in mock, WNT3, or WNT3 plus SFRP1 inhibitor conditions (shown relative to mock; ANOVA, Games-Howell post hoc, $p \leq 0.009)$.

projection neurons, but did not affect the directly adjacent FOXP1positive layer 3-4 subpopulation. Tight spatiotemporal translational control via our proposed mechanism may be important in neocortical development, and slight alterations in extrinsic signals driving intrinsic translation mechanisms could lead to a myriad of deficiencies related to premature or delayed mRNA translation in neurodevelopmental disorders (Darnell et al., 2011).

We expect there is a highly complex set of events by which the composition of R-proteins within the ribosome are modified. This is a challenging biological question, as the ribosome is a massive macromolecular complex composed of $\geq 80$ R-proteins, some of which can differentially associate with large and small ribosomal subunits to modulate mRNA translation specificity (Xue and Barna, 2012). We found that RPL7 and RPL10 change levels inversely in polysomes during development while RPL34 remained unchanged, suggesting that at least a subset undergo specific regulation, as in our findings when we compared WT and Wnt3-cKO neocortices. To identify the magnitude of ribosome signature diversity, it will be necessary to decipher how both specific and more global changes among R-proteins occur in the translation machinery.
The stoichiometry of RPL and RPS R-proteins in neocortical 40S-60S-80S and polysomal complexes may influence the translation of specific mRNAs. RPL7 localizes to the 60S "stalk" region important in peptide elongation, directly interacting with RPL10 (Wahl and Möller, 2002; Datta et al., 2005; Diaconu et al., 2005), and has been shown to bind mRNAs via a specific binding motif (Hemmerich et al., 1997). RPL13a-also identified in our mass spectrometry data-targets the 3'UTR to block ribosomal assembly and translation initiation of specific mRNAs (Kapasi et al., 2007). Interestingly, evolutionary analysis suggests that the ribosome is a phylogenetically divergent structure, possibly corresponding to the specific demands of different organisms or tissues (Roberts et al., 2008). As studies in the developing axial skeleton suggest (Kondrashov et al., 2011; Xue et al., 2015), the patterning of complex tissues via specific ribosomal machinery may represent a conserved developmental mechanism. Dissecting how the combinatorial composition of the ribosome may contribute to a cell-type-specific translation of its transcriptome will be an interesting direction for future study.

Thus, we describe a possible mechanism by which rapid spatiotemporal control of gene expression occurs in the developing 
A

\section{Spatio-temporally regulated ribosome signature and mRNA translation}

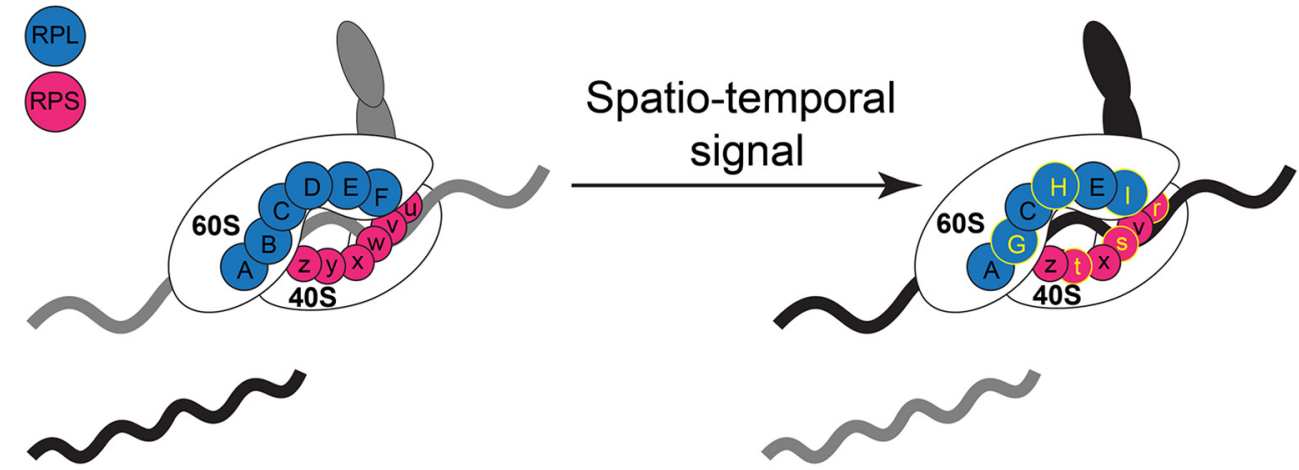

B

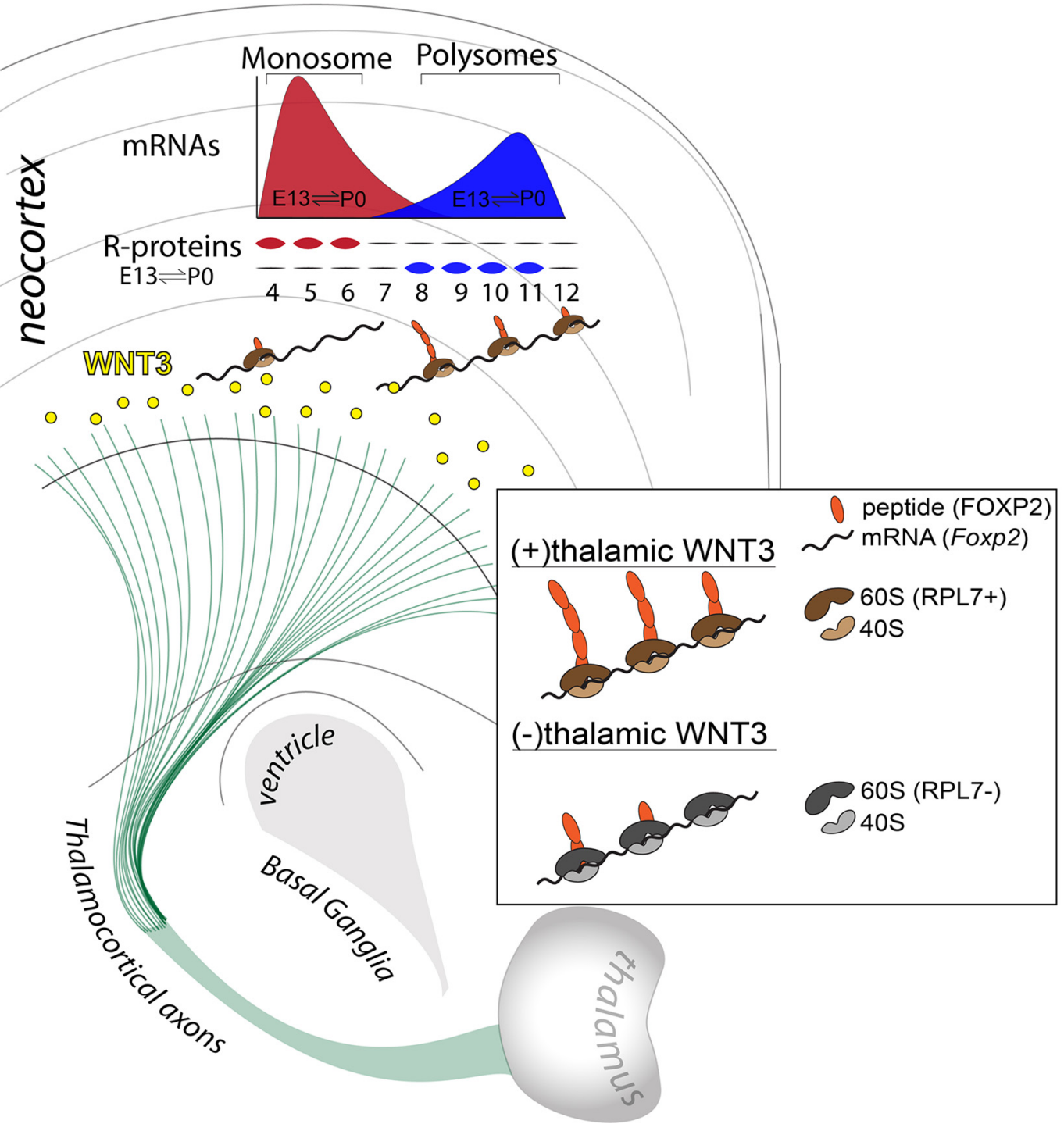

Figure 7. Model for the spatiotemporal regulation of mRNA translation during neocortical development. A, Small (40S) and large (60S) ribosomal subunits combined contain $\sim 80$ ribosomal proteins (R-proteins). R-proteins associated with the small (RPS, pink) and large (RPL, blue) subunits may differentially associate with these subunits in response to timed signals during neocortical development, coordinated with the dynamic translation of subsets of mRNAs. $\boldsymbol{B}$, Schematic of how timed WNT3 secretion from thalamocortical axons regulates mRNA translation in the developing neocortex. This may influence the spatiotemporal translation of specific mRNAs, such as Foxp2, that drive neocortical projection neuron differentiation. 
neocortex. Future work will refine the resolution of ribosome structure and polysome profiling for distinct neocortical cell subtypes, detailing the ribosome signatures and signaling molecules regulating the specificity of mRNA translation driving neocortical development.

\section{References}

Anderson MP, Mochizuki T, Xie J, Fischler W, Manger JP, Talley EM, Scammell TE, Tonegawa S (2005) Thalamic Cav3.1 T-type Ca2+ channel plays a crucial role in stabilizing sleep. Proc Natl Acad Sci U S A 102:17431748. CrossRef Medline

Ashburner M, Ball CA, Blake JA, Botstein D, Butler H, Cherry JM, Davis AP, Dolinski K, Dwight SS, Eppig JT, Harris MA, Hill DP, Issel-Tarver L, Kasarskis A, Lewis S, Matese JC, Richardson JE, Ringwald M, Rubin GM, Sherlock G (2000) Gene Ontology: tool for the unification of biology. Nat Genet 25:25-29. CrossRef Medline

Ayoub AE, Oh S, Xie Y, Leng J, Cotney J, Dominguez MH, Noonan JP, Rakic P (2011) Transcriptional programs in transient embryonic zones of the cerebral cortex defined by high-resolution mRNA sequencing. Proc Natl Acad Sci U S A 108:14950-14955. CrossRef Medline

Barrow JR, Thomas KR, Boussadia-Zahui O, Moore R, Kemler R, Capecchi MR, McMahon AP (2003) Ectodermal Wnt3/beta-catenin signaling is required for the establishment and maintenance of the apical ectodermal ridge. Genes Dev 17:394-409. CrossRef Medline

Belgard TG, Marques AC, Oliver PL, Abaan HO, Sirey TM, HoerderSuabedissen A, García-Moreno F, Molnár Z, Margulies EH, Ponting CP (2011) NeuroResource: a transcriptomic atlas of mouse neocortical layers. Neuron 71:605-616. CrossRef Medline

Breunig JJ, Haydar TF, Rakic P (2011) Neural stem cells: historical perspective and future prospects. Neuron 70:614-625. CrossRef Medline

Brooks SS, Wall AL, Golzio C, Reid DW, Kondyles A, Willer JR, Botti C, Nicchitta CV, Katsanis N, Davis EE (2014) A novel ribosomopathy caused by dysfunction of X-linked microcephaly in humans. Genetics 198:723-733. CrossRef Medline

Castelo-Branco G, Wagner J, Rodriguez FJ, Kele J, Sousa K, Rawal N, Pasolli HA, Fuchs E, Kitajewski J, Arenas E (2003) Differential regulation of midbrain dopaminergic neuron development by Wnt-1, Wnt-3a, and Wnt-5a. Proc Natl Acad Sci U S A 100:12747-12752. CrossRef Medline

Choe Y, Siegenthaler JA, Pleasure SJ (2012) A cascade of morphogenic signaling initiated by the meninges controls corpus callosum formation. Neuron 73:698-712. CrossRef Medline

Darnell JC, Van Driesche SJ, Zhang C, Hung KY, Mele A, Fraser CE, Stone EF, Chen C, Fak JJ, Chi SW, Licatalosi DD, Richter JD, Darnell RB (2011) FMRP stalls ribosomal translocation on mRNAs linked to synaptic function and autism. Cell 146:247-261. CrossRef Medline

Datta PP, Sharma MR, Qi L, Frank J, Agrawal RK (2005) Interaction of the $\mathrm{G}$ ' domain of elongation factor $\mathrm{G}$ and the $\mathrm{C}$-terminal domain of ribosomal protein L7/L12 during translocation as revealed by cryo-EM. Mol Cell 20:723-731. CrossRef Medline

DeBoer EM, Kraushar ML, Hart RP, Rasin MR (2013) Post-transcriptional regulatory elements and spatiotemporal specification of neocortical stem cells and projection neurons. Neuroscience 248:499-528. CrossRef Medline

DeBoer EM, Azevedo R, Vega TA, Brodkin J, Akamatsu W, Okano H, Wagner GC, Rasin MR (2014) Prenatal deletion of the RNA-binding protein $\mathrm{HuD}$ disrupts postnatal cortical circuit maturation and behavior. J Neurosci 34:3674-3686. CrossRef Medline

Diaconu M, Kothe U, Schlünzen F, Fischer N, Harms JM, Tonevitsky AG, Stark H, Rodnina MV, Wahl MC (2005) Structural basis for the function of the ribosomal L7/12 stalk in factor binding and GTPase activation. Cell 121:991-1004. CrossRef Medline

Ferland RJ, Cherry TJ, Preware PO, Morrisey EE, Walsh CA (2003) Characterization of Foxp2 and Foxp1 mRNA and protein in the developing and mature brain. J Comp Neurol 460:266-279. CrossRef Medline

Fertuzinhos S, Li M, Kawasawa YI, Ivic V, Franjic D, Singh D, Crair M, Sestan N (2014) Laminar and temporal expression dynamics of coding and noncoding RNAs in the mouse neocortex. Cell Rep 6:938-950. CrossRef Medline

French CA, Groszer M, Preece C, Coupe AM, Rajewsky K, Fisher SE (2007) Generation of mice with a conditional Foxp2 null allele. Genesis 45:440446. CrossRef Medline
Fromont-Racine M, Senger B, Saveanu C, Fasiolo F (2003) Ribosome assembly in eukaryotes. Gene 313:17-42. CrossRef Medline

Gong S, Zheng C, Doughty ML, Losos K, Didkovsky N, Schambra UB, Nowak NJ, Joyner A, Leblanc G, Hatten ME, Heintz N (2003) A gene expression atlas of the central nervous system based on bacterial artificial chromosomes. Nature 425:917-925. CrossRef Medline

Gorski JA, Talley T, Qiu M, Puelles L, Rubenstein JL, Jones KR (2002) Cortical excitatory neurons and glia, but not GABAergic neurons, are produced in the Emx1-expressing lineage. J Neurosci 22:6309-6314. Medline

Groszer M, Keays DA, Deacon RM, de Bono JP, Prasad-Mulcare S, Gaub S, Baum MG, French CA, Nicod J, Coventry JA, Enard W, Fray M, Brown SD, Nolan PM, Pääbo S, Channon KM, Costa RM, Eilers J, Ehret G, Rawlins JN, Fisher SE (2008) Impaired synaptic plasticity and motor learning in mice with a point mutation implicated in human speech deficits. Curr Biol 18:354-362. CrossRef Medline

Hemmerich P, Bosbach S, von Mikecz A, Krawinkel U (1997) Human ribosomal protein L7 binds RNA with an alpha-helical arginine-rich and lysine-rich domain. Eur J Biochem 245:549-556. CrossRef Medline

Henras AK, Soudet J, Gérus M, Lebaron S, Caizergues-Ferrer M, Mougin A, Henry Y (2008) The post-transcriptional steps of eukaryotic ribosome biogenesis. Cell Mol life Sci 65:2334-2359. CrossRef Medline

Huang da W, Sherman BT, Lempicki RA (2009a) Systematic and integrative analysis of large gene lists using DAVID bioinformatics resources. Nat Protoc 4:44-57. Medline

Huang da W, Sherman BT, Lempicki RA (2009b) Bioinformatics enrichment tools: paths toward the comprehensive functional analysis of large gene lists. Nucleic Acids Res 37:1-13. CrossRef Medline

Inoki K, Ouyang H, Zhu T, Lindvall C, Wang Y, Zhang X, Yang Q, Bennett C, Harada Y, Stankunas K, Wang CY, He X, MacDougald OA, You M, Williams BO, Guan KL (2006) TSC2 integrates Wnt and energy signals via a coordinated phosphorylation by AMPK and GSK3 to regulate cell growth. Cell 126:955-968. CrossRef Medline

Jablonska B, Scafidi J, Aguirre A, Vaccarino F, Nguyen V, Borok E, Horvath TL, Rowitch DH, Gallo V (2012) Oligodendrocyte regeneration after neonatal hypoxia requires FoxO1-mediated p27Kip1 expression. J Neurosci 32:14775-14793. CrossRef Medline

Jackson RJ, Hellen CU, Pestova TV (2010) The mechanism of eukaryotic translation initiation and principles of its regulation. Nat Rev Mol Cell Biol 11:113-127. CrossRef Medline

Kanehisa M, Goto S, Sato Y, Kawashima M, Furumichi M, Tanabe M (2014) Data, information, knowledge and principle: back to metabolism in KEGG. Nucleic Acids Res 42:D199-D205. CrossRef Medline

Kang HJ, Kawasawa YI, Cheng F, Zhu Y, Xu X, Li M, Sousa AM, Pletikos M, Meyer KA, Sedmak G, Guennel T, Shin Y, Johnson MB, Krsnik Z, Mayer S, Fertuzinhos S, Umlauf S, Lisgo SN, Vortmeyer A, Weinberger DR, et al. (2011) Spatio-temporal transcriptome of the human brain. Nature 478: 483-489. CrossRef Medline

Kapasi P, Chaudhuri S, Vyas K, Baus D, Komar AA, Fox PL, Merrick WC, Mazumder B (2007) L13a blocks 48 S assembly: role of a general initiation factor in mRNA-specific translational control. Mol Cell 25:113-126. CrossRef Medline

Katsanou V, Milatos S, Yiakouvaki A, Sgantzis N, Kotsoni A, Alexiou M, Harokopos V, Aidinis V, Hemberger M, Kontoyiannis DL (2009) The RNA-binding protein Elavl1/HuR is essential for placental branching morphogenesis and embryonic development. Mol Cell Biol 29:27622776. CrossRef Medline

Kondrashov N, Pusic A, Stumpf CR, Shimizu K, Hsieh AC, Xue S, Ishijima J, Shiroishi T, Barna M (2011) Ribosome-mediated specificity in Hox mRNA translation and vertebrate tissue patterning. Cell 145:383-397. CrossRef Medline

Kraushar ML, Thompson K, Wijeratne HR, Viljetic B, Sakers K, Marson JW, Kontoyiannis DL, Buyske S, Hart RP, Rasin MR (2014) Temporally defined neocortical translation and polysome assembly are determined by the RNA-binding protein $\mathrm{Hu}$ antigen R. Proc Natl Acad Sci U S A 111: E3815-EE3824. CrossRef Medline

Kriegstein A, Alvarez-Buylla A (2009) The glial nature of embryonic and adult neural stem cells. Annu Rev Neurosci 32:149-184. CrossRef Medline

Kutejova E, Briscoe J, Kicheva A (2009) Temporal dynamics of patterning by morphogen gradients. Curr Opin Genet Dev 19:315-322. CrossRef Medline 
Kwan KY, Lam MM, Johnson MB, Dube U, Shim S, Rašin MR, Sousa AM, Fertuzinhos S, Chen JG, Arellano JI, Chan DW, Pletikos M, Vasung L, Rowitch DH, Huang EJ, Schwartz ML, Willemsen R, Oostra BA, Rakic P, Heffer M, et al. (2012a) Species-dependent posttranscriptional regulation of NOS1 by FMRP in the developing cerebral cortex. Cell 149:899-911. CrossRef Medline

Kwan KY, Sestan N, Anton ES (2012b) Transcriptional co-regulation of neuronal migration and laminar identity in the neocortex. Development 139:1535-1546. CrossRef Medline

Lang J, Maeda Y, Bannerman P, Xu J, Horiuchi M, Pleasure D, Guo F (2013) Adenomatous polyposis coli regulates oligodendroglial development. J Neurosci 33:3113-3130. CrossRef Medline

Langseth AJ, Munji RN, Choe Y, Huynh T, Pozniak CD, Pleasure SJ (2010) Wnts influence the timing and efficiency of oligodendrocyte precursor cell generation in the telencephalon. J Neurosci 30:13367-13372. CrossRef Medline

Leone DP, Srinivasan K, Chen B, Alcamo E, McConnell SK (2008) The determination of projection neuron identity in the developing cerebral cortex. Curr Opin Neurobiol 18:28-35. CrossRef Medline

López-Bendito G, Molnár Z (2003) Thalamocortical development: how are we going to get there? Nat Rev Neurosci 4:276-289. CrossRef Medline

Machon O, Backman M, Machonova O, Kozmik Z, Vacik T, Andersen L, Krauss S (2007) A dynamic gradient of Wnt signaling controls initiation of neurogenesis in the mammalian cortex and cellular specification in the hippocampus. Dev Biol 311:223-237. CrossRef Medline

Mazumder B, Seshadri V, Fox PL (2003a) Translational control by the $3^{\prime}$ UTR: the ends specify the means. Trends Biochem Sci 28:91-98. CrossRef Medline

Mazumder B, Sampath P, Seshadri V, Maitra RK, DiCorleto PE, Fox PL (2003b) Regulated release of L13a from the 60S ribosomal subunit as a mechanism of transcript-specific translational control. Cell 115:187-198. CrossRef Medline

Miller JA, Ding SL, Sunkin SM, Smith KA, Ng L, Szafer A, Ebbert A, Riley ZL, Royall JJ, Aiona K, Arnold JM, Bennet C, Bertagnolli D, Brouner K, Butler S, Caldejon S, Carey A, Cuhaciyan C, Dalley RA, Dee N, et al. (2014) Transcriptional landscape of the prenatal human brain. Nature 508:199206. CrossRef Medline

Molyneaux BJ, Arlotta P, Menezes JR, Macklis JD (2007) Neuronal subtype specification in the cerebral cortex. Nat Rev Neurosci 8:427-437. CrossRef Medline

O'Leary DD, Chou SJ, Sahara S (2007) Area patterning of the mammalian cortex. Neuron 56:252-269. CrossRef Medline
Rakic P (2009) Evolution of the neocortex: a perspective from developmental biology. Nat Rev Neurosci 10:724-735. CrossRef Medline

Rash BG, Grove EA (2006) Area and layer patterning in the developing cerebral cortex. Curr Opin Neurobiol 16:25-34. CrossRef Medline

Rasin MR, Gazula VR, Breunig JJ, Kwan KY, Johnson MB, Liu-Chen S, Li HS, Jan LY, Jan YN, Rakic P, Sestan N (2007) Numb and Numbl are required for maintenance of cadherin-based adhesion and polarity of neural progenitors. Nat Neurosci 10:819-827. CrossRef Medline

Roberts E, Sethi A, Montoya J, Woese CR, Luthey-Schulten Z (2008) Molecular signatures of ribosomal evolution. Proc Natl Acad Sci U S A 105: 13953-13958. CrossRef Medline

Schwanhäusser B, Busse D, Li N, Dittmar G, Schuchhardt J, Wolf J, Chen W, Selbach M (2011) Global quantification of mammalian gene expression control. Nature 473:337-342. CrossRef Medline

Thompson K, DiBona VL, Dubey A, Crockett DP, Rasin M-R (2010) Acute adaptive responses of central sensorimotor neurons after spinal cord injury. Transl Neurosci 1:268-278.

Trapnell C, Roberts A, Goff L, Pertea G, Kim D, Kelley DR, Pimentel H, Salzberg SL, Rinn JL, Pachter L (2012) Differential gene and transcript expression analysis of RNA-seq experiments with TopHat and Cufflinks. Nat Protoc 7:562-578. CrossRef Medline

Tsai HH, Li H, Fuentealba LC, Molofsky AV, Taveira-Marques R, Zhuang H, Tenney A, Murnen AT, Fancy SP, Merkle F, Kessaris N, Alvarez-Buylla A, Richardson WD, Rowitch DH (2012) Regional astrocyte allocation regulates CNS synaptogenesis and repair. Science 337:358-362. CrossRef Medline

Tsui D, Vessey JP, Tomita H, Kaplan DR, Miller FD (2013) FoxP2 regulates neurogenesis during embryonic cortical development. J Neurosci 33: 244-258. CrossRef Medline

Wahl MC, Möller W (2002) Structure and function of the acidic ribosomal stalk proteins. Curr Protein Pept Sci 3:93-106. CrossRef Medline

Washburn MP, Wolters D, Yates JR 3rd (2001) Large-scale analysis of the yeast proteome by multidimensional protein identification technology. Nat Biotechnol 19:242-247. CrossRef Medline

Xue S, Barna M (2012) Specialized ribosomes: a new frontier in gene regulation and organismal biology. Nat Rev Mol Cell Biol 13:355-369. CrossRef Medline

Xue S, Tian S, Fujii K, Kladwang W, Das R, Barna M (2015) RNA regulons in Hox $5^{\prime}$ UTRs confer ribosome specificity to gene regulation. Nature 517: 33-38. CrossRef Medline 